\title{
BARRIERS OF ADOPTING THE MODERN IRRIGATION SYSTEMS IN THE MEDINA IN SAUDI ARABIA
}

(Received:19.4.2011)

\author{
By \\ M. S. Al-Shayaa \\ Department of Agricultural Extension and Rural Sociology, Food and Agriculture Sciences, \\ King Saud University, Kingdom of Saudi Arabia
}

\begin{abstract}
This study aimed at identifying the obstacles to the adoption of modern irrigation systems in Medina, KSA. The technical and economic constraints were identified and the degree of knowledge of farmers on these irrigation systems was determined. The objectives of the study were achieved through the application of descriptive statistical analysis and distribution of Brnilloli, that is also known as the binomial probability distribution. The study revealed that: (1) Despite the farmers have high degree of knowledge on the innovative irrigation methods, still more than $67 \%$ of the sampled population use the flood irrigation method, whereas only $33 \%$ of them employ drip irrigation and the other modern irrigation methods; (2) As high as $82 \%$ of the farmers faced technical obstacles in adopting the modern irrigation systems whereas $3.01 \%$ of them faced the problems on the blockage of drippers, $3.0 \%$ on filters, and $2.92 \%$ on springs; (3) Only $6.6 \%$ of the farmers were faced with the technical problems while using modern irrigation systems. However, the level of technical problems experienced by the $53.9 \%$ of the farmers was medium to high at the $95 \%$ confidence interval; (4) About $7.6 \%$ of the farmers faced the economic problems in getting the modern irrigation systems installed at their farms and $92.4 \%$ of the farmers faced with the middle level economic problems in this respect at the 95\% confidence interval; (5) Lack of funding from banks or the companies remained the most important economic constraints, with an average account amounted to 4.64 and 4.61 each, respectively, (6): A positive correlation between some personal characteristics and the variables of the study was observed.

The study recommends establishing a Fund for Agricultural Development Programme to enable farmers to practice the judicious use of water resources for agricultural purposes. Provision of this sort of funding would help farmers replace the traditional irrigation systems with the modern irrigation systems. In addition, the Ministry of Agriculture needs to encourage the farmers, educate and guide them on the use of water and how to overcome the technical constraints faced while using the modern irrigation systems to improve the water-use efficiency
\end{abstract}

Key words: barriers to adoption, modern irrigation systems, the city of Medina.

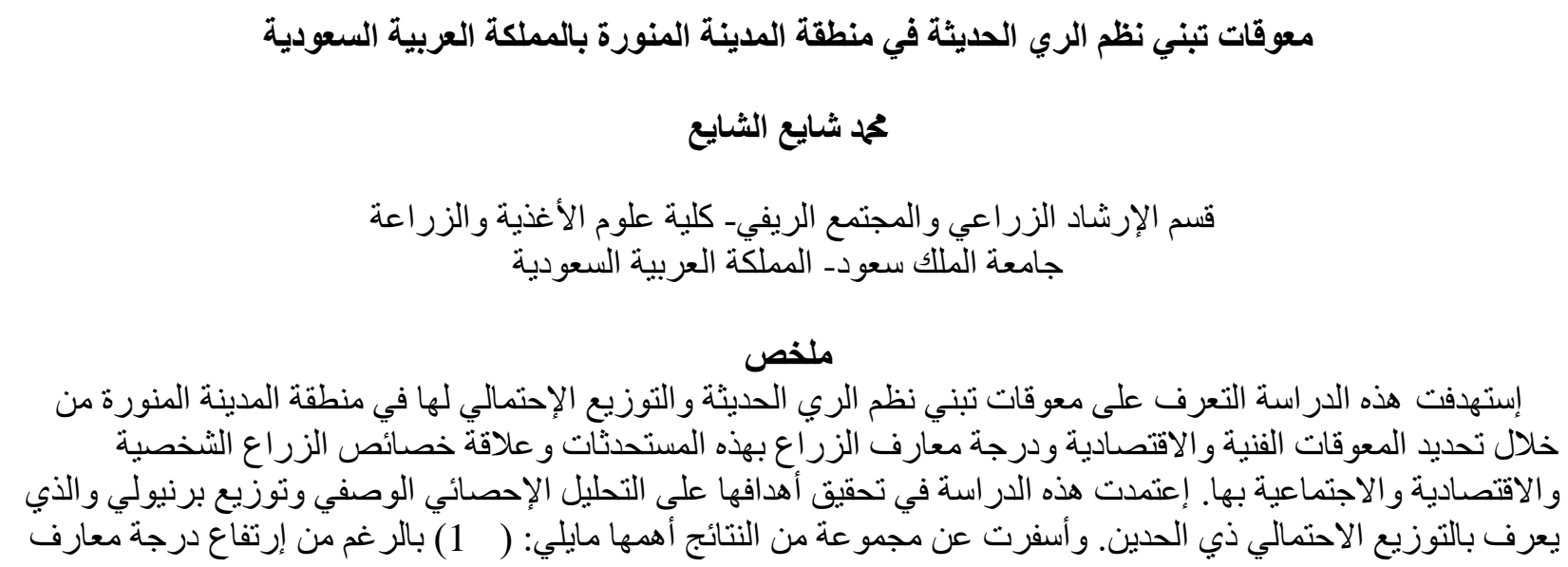




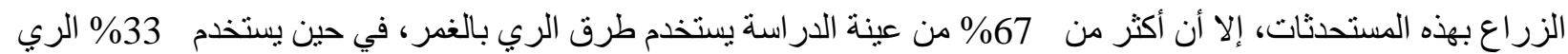

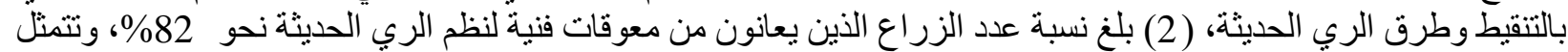

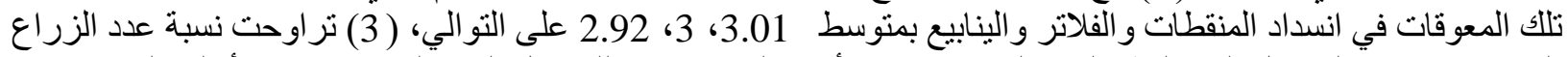

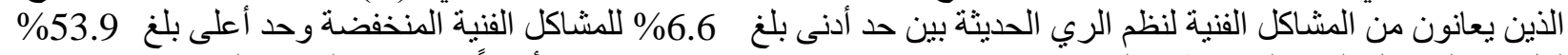

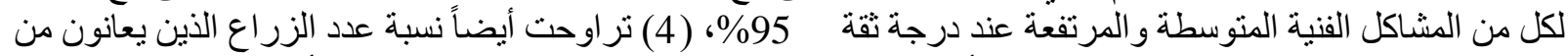

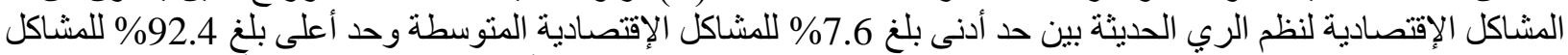

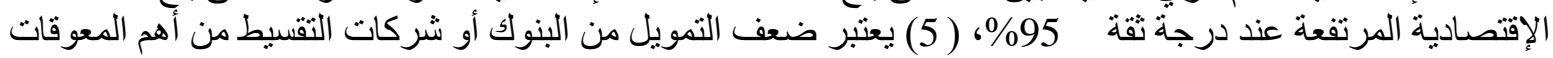

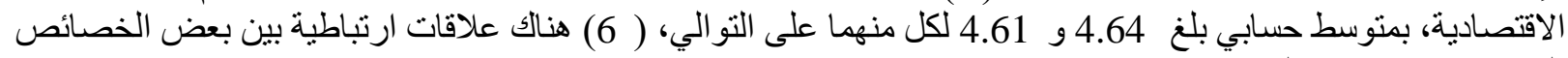
الثخصية ومتغير ات الدر استة.

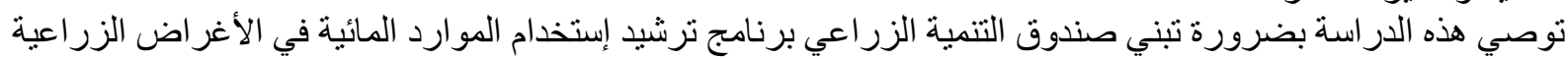

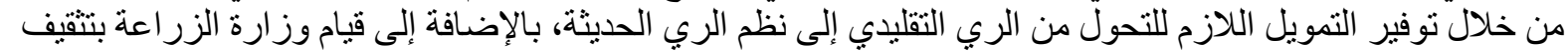

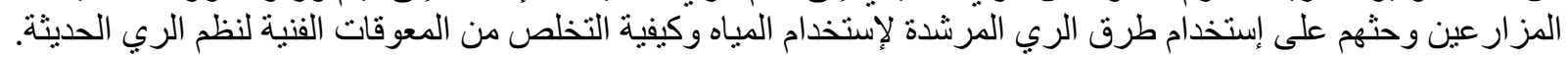

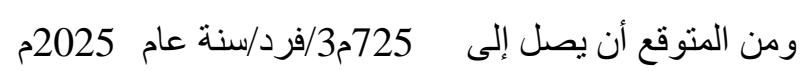
(Faruqui et al., 2001)

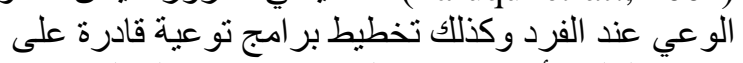

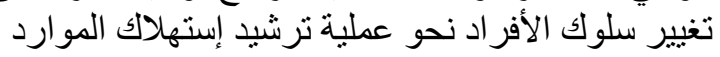
المائية.

\section{2. - 2 - 2 مشكلة الدراسة}

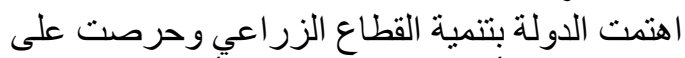

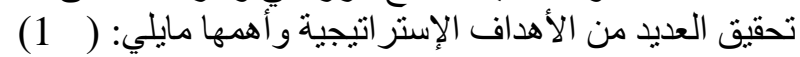

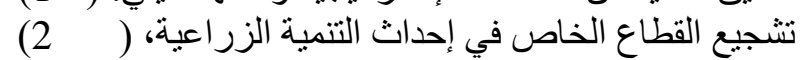

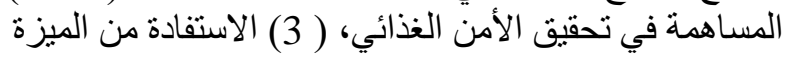

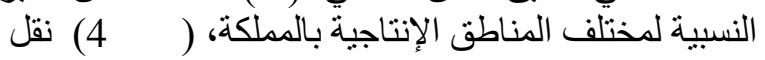

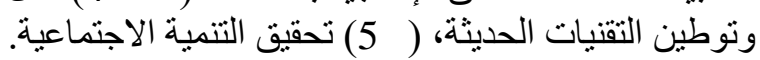

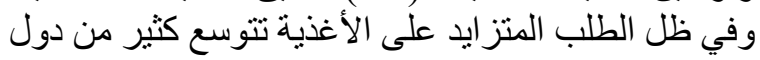

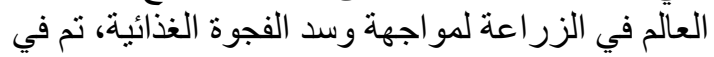

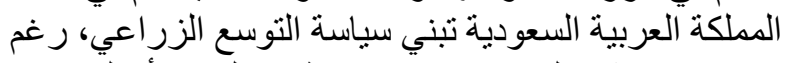

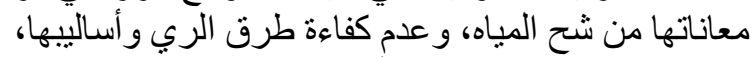

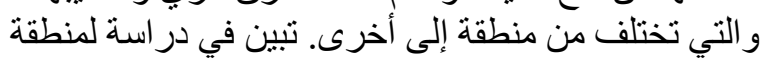

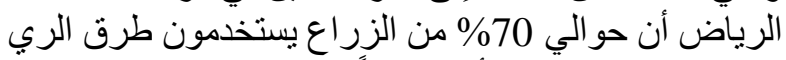
بالغمر وهي الطريقة الأكثر هدر أ للمياه ( العتيبي،

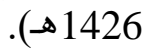

تعاني منطقة المدينة المنورة من شح المو ارد المائية نظر اً

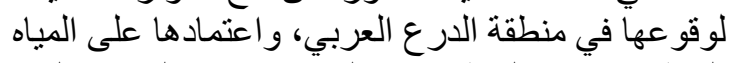

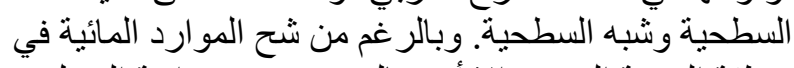

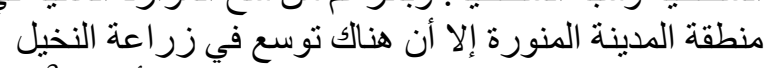

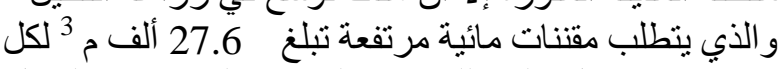

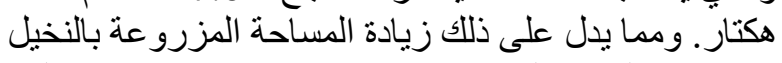

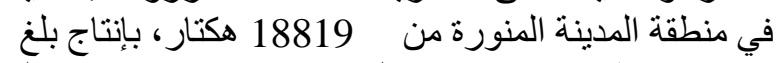

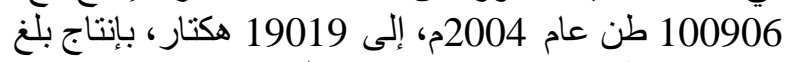
123591 طن عام 2008م (وزارة الزر اعة، 2004 2009م).

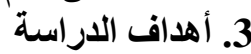

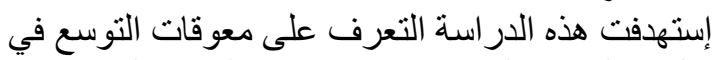

طرق الري الحديثة المستخدمة في منطقة المدينة المنورة وذلك من خلال در استة كل من:

1 - الخصائص الثخصية والإجتماعية و الإقتصادية للزراع المبحوثين.

2 - المعوقات المعرفية و الفنية و الإقتصادية لتبني نظم الري

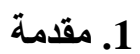

تعتبر الموارد المائية من أهم محددات التنمية الإقتصادية

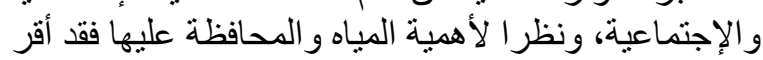

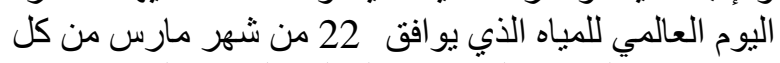

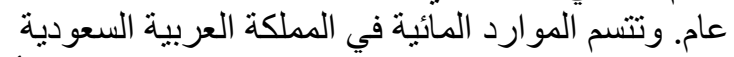

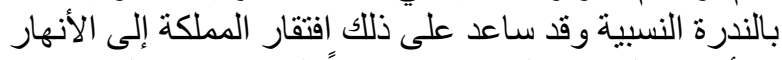

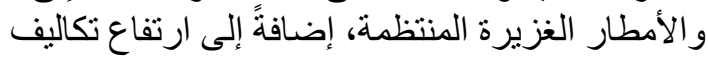

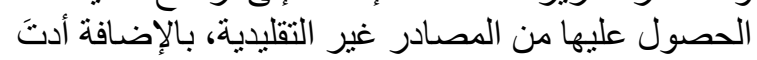

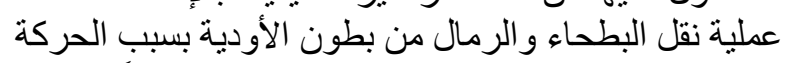

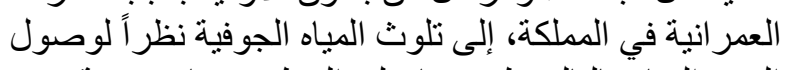

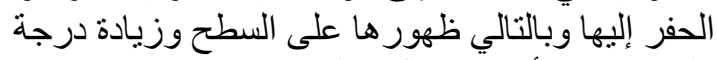

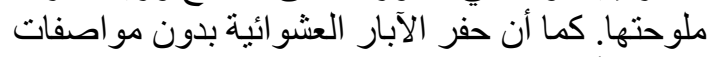

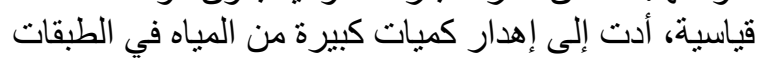

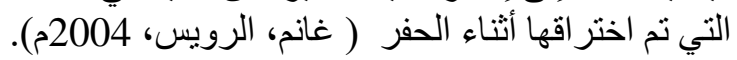

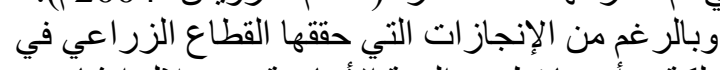

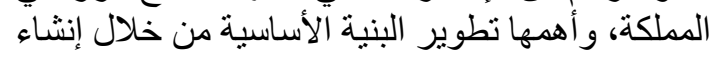

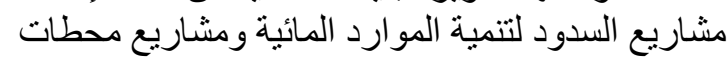

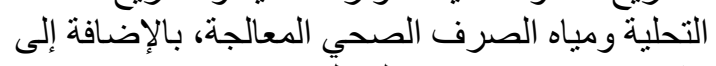

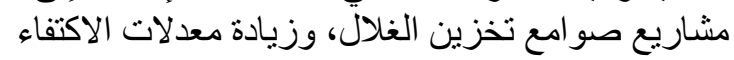

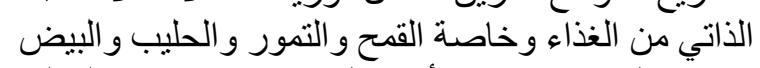

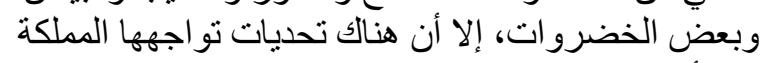

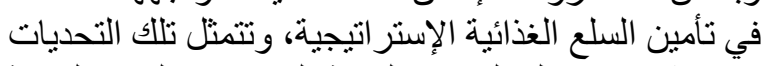

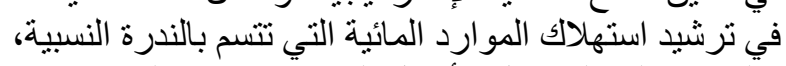

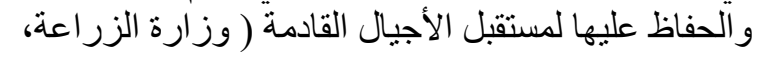
. 2006

تعتبر المملكة العربية السعودية من أكثر دول العالم شحاً

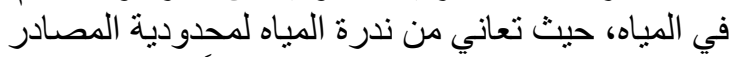

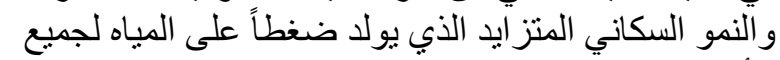

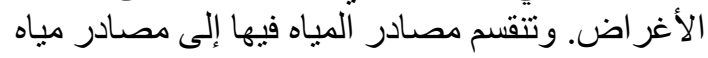

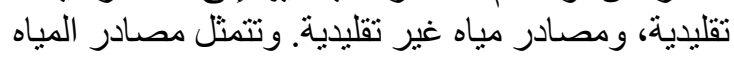

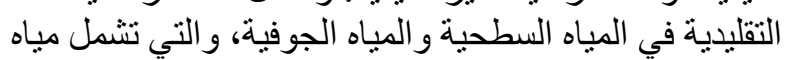

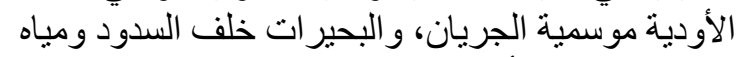

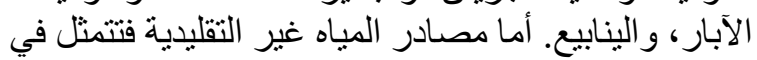

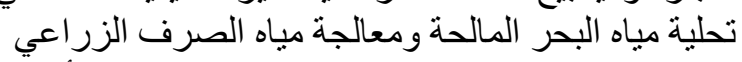

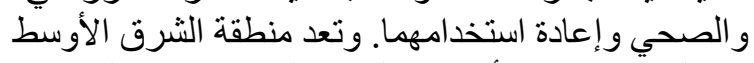

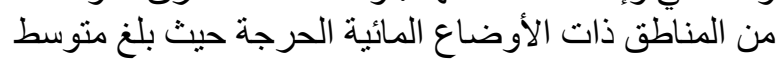

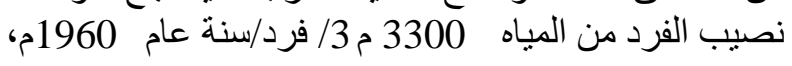


ولمو اجهة هذه المعوقات نظهر نظم الري الحديثة الخاصة

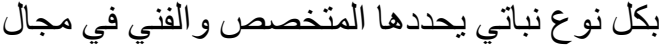

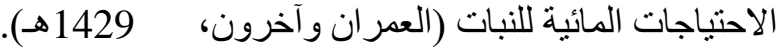

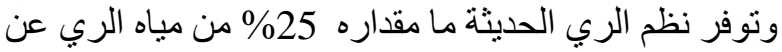

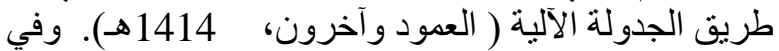

ري النخيل تعد نظم الري بالتنقيط أعلى كفاءة من حيث الألى

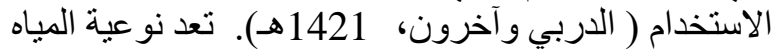

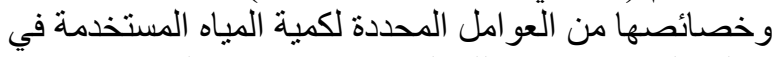

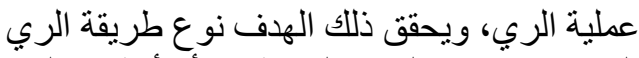
المستخدمة ويعد الري بالتنقيط من أكفأ طرق الرئ الري الرئ الحديثة

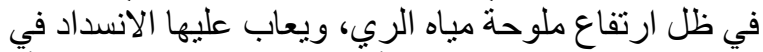

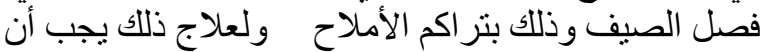
تكون فتحات المنقطات واسعة (العمر ان و آخرون،

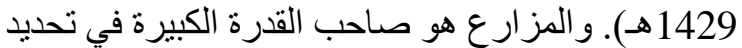
حجم المياه المستهلكة وذلك من خلال فهم الاحتياج المائي

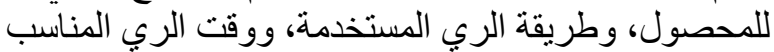

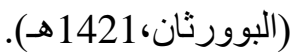
وبصفة عامة يعد الإنسان هو المحدد الرئيسي لحجم المياه

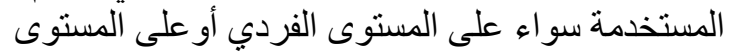

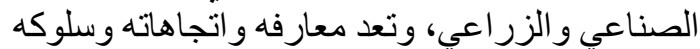

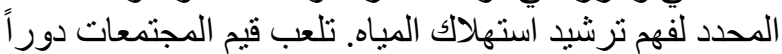

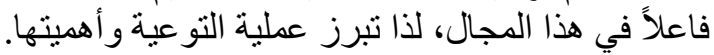

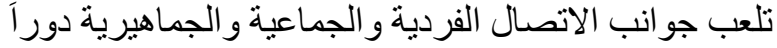
في نشر الوعي و الثقافة ( Park,2003). تلعب جهات الفرية متعددة

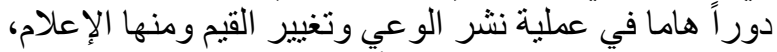

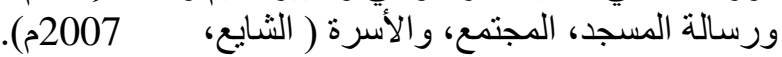

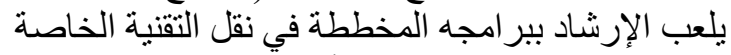

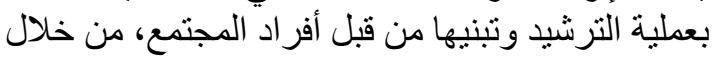

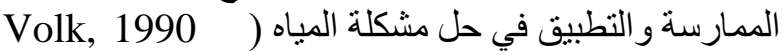
(William, 1990 ; Hungerford, and التركيز على الوسائل الأكثر شيو عاً واستخداماً بين الناس

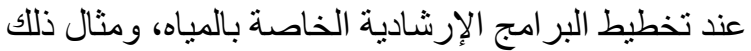

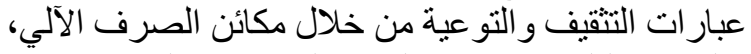
و البر امج التلفزيونية ذات الطابع الترفيهي ( الثايع، 2007م).

وفي مجال تبني المبنكرات أوضح (Rogers,1995)

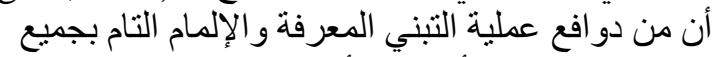

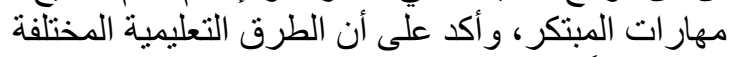

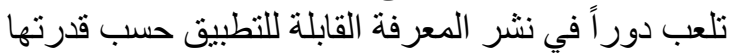

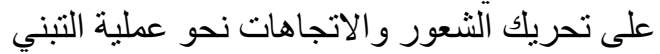

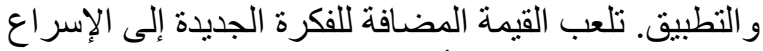

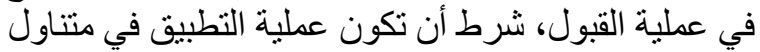

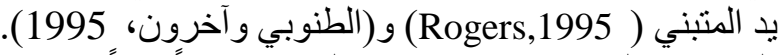

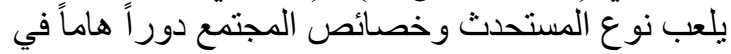

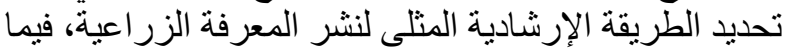

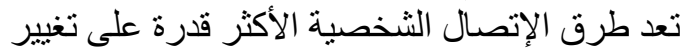
الإتجاهات و إكساب المهار ات الرات (الريماوي وآخرون، 1996

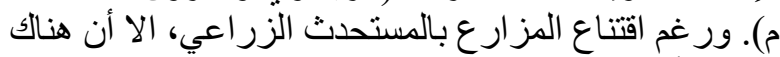
عو امل أخرى تحدد درجة التبني كصافي العائد، وسهولة الألة التهاك

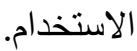

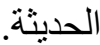

3 - التوزيع الإحتمالي لمدى إستخدام طرق الري التقليدية و الحديثة في منطقة المدينة المنورة.

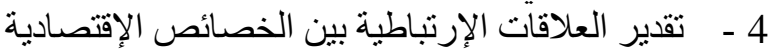

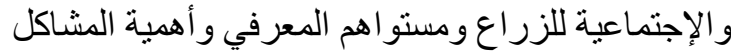
الفنية و الإقتصادية لطرق الرئية الري الحديثة.

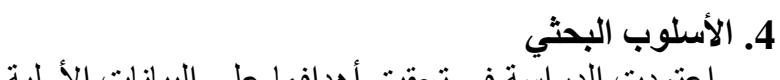
اعتمدت الدراسة في تحقيق أهدافها على البيانات الاولية

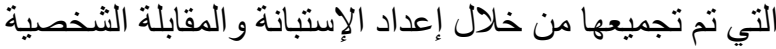

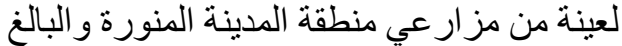

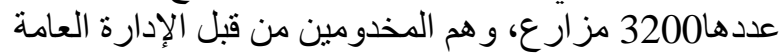

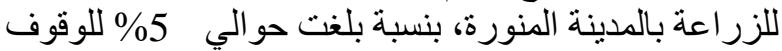

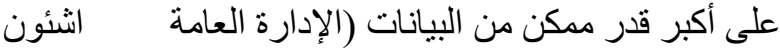

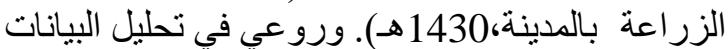

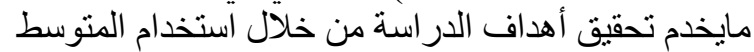

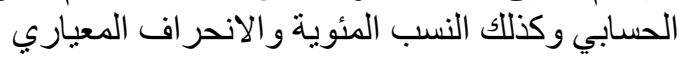
و العلاقات الإرنباطية باستخدام البرنامج الإحصائي

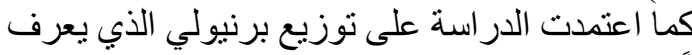

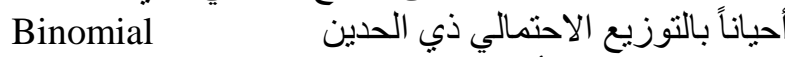

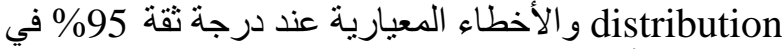
تقدير نسبة أو احتمال معوقات تبني استخدام تقنيات الرئ الري

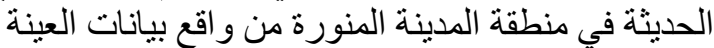
البحتية. و عند تقدير نسبة أو احتمال استخدام التقنيات الحيثية الحيثة

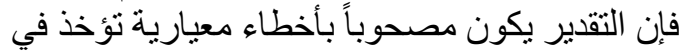

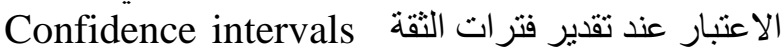

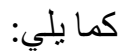

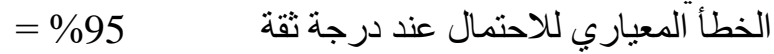

$$
\begin{aligned}
& \pm 1.96 * \sqrt{\frac{P(1-P)}{N}} \\
& \text { فترة الثقة 95\% للاحتمال }=1.96 * \sqrt{\frac{P(1-P)}{N}}
\end{aligned}
$$
حيث أن: P Pمثل احتمال استخدام التقنيات الحديثة في الري

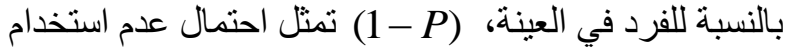

$$
\text { التقنيات الحديثة بالنسبة للفرد، }
$$

(Makridakis et al., 1993)

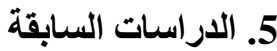
تستخدم المياه في أغر اض متعددة، منها المنزلية

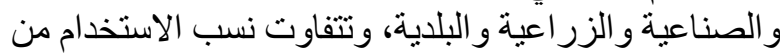

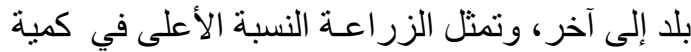

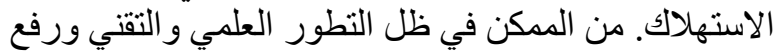

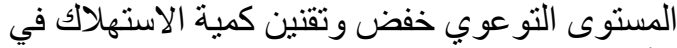
الأغر اض المنزلية و الصناعية بوسئلئل متعددة إدارية وفنية لإنية، فيما تعد الطرق الحديثة للري من عو امل التئن التقنين و الترشيد في

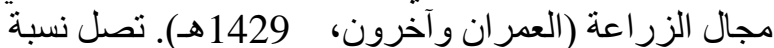
الاستهلاك الزر اعي للمياه إلى 85 \%

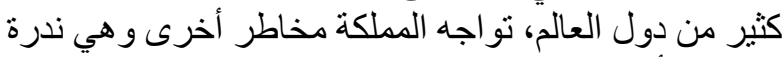
المياه و الأمطار في هذه المنطقة الصحر اوية الجافة. 


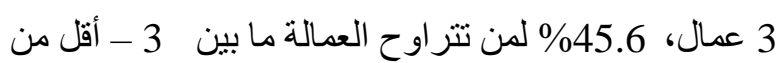

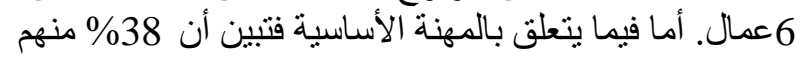

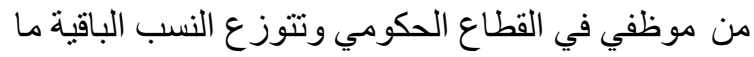

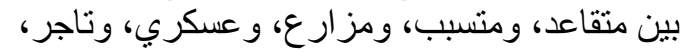
وموظف قطاع خاص بنسبة 16.5\%، 15.2\%، 13.9\%

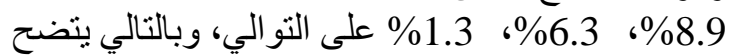
إنخفاض نسبة من يمتهنون الزر اعة كمهنة أساسيّة حيث تبين

أن 86.1\% من الزر اع تثكل الزر اعة بالنسبة لهم مهنة

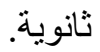

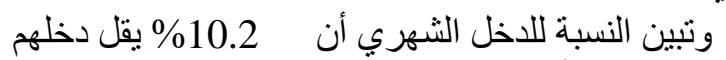

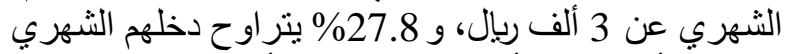
بين 3 - أقل من 5 ألف ريال، في حين أن 20.3 20.

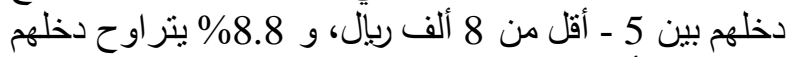

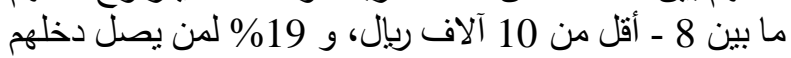

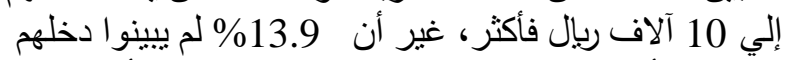

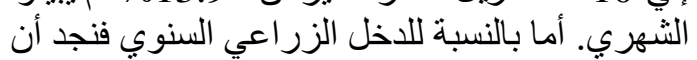

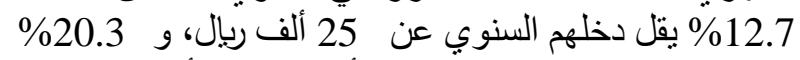

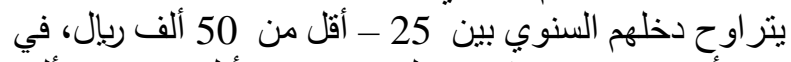

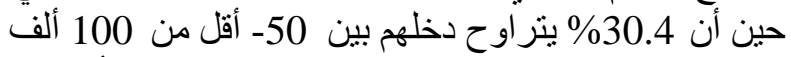

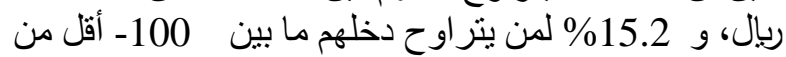

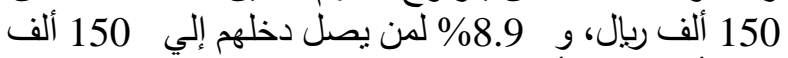

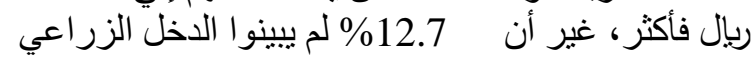

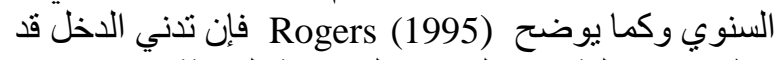

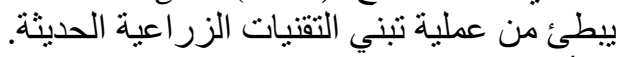

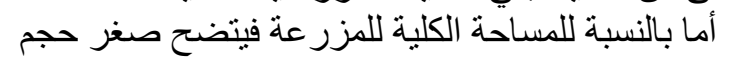

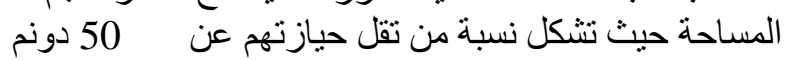

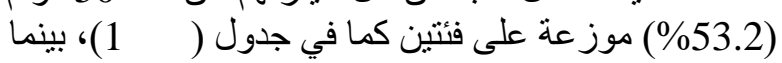

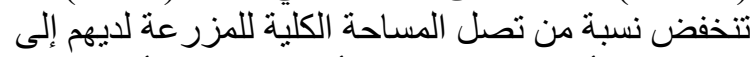

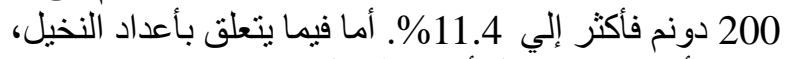

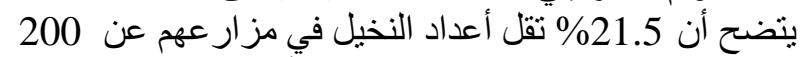

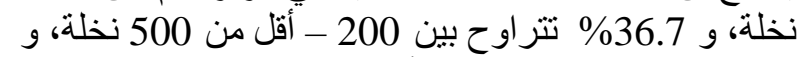

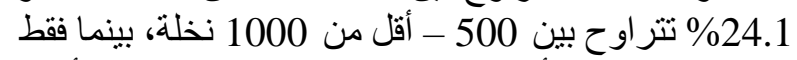

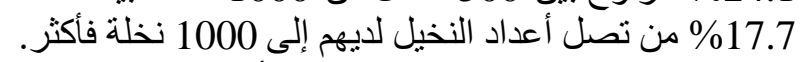

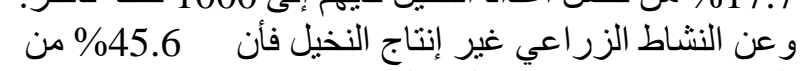

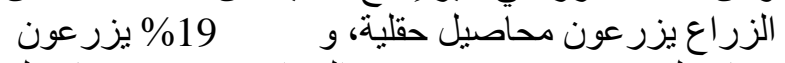

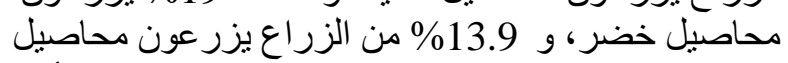

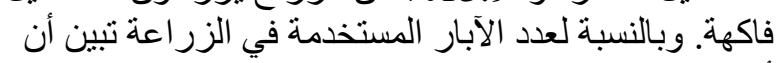

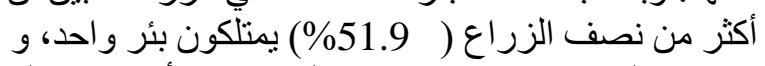

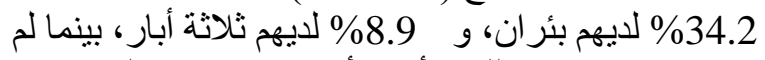

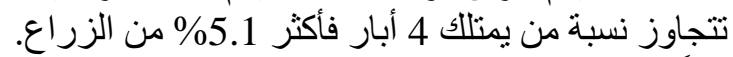

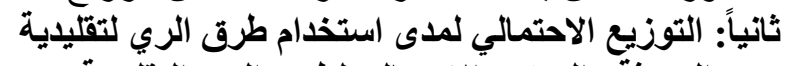

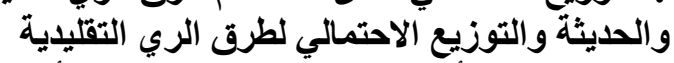

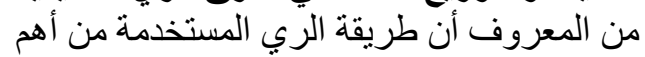

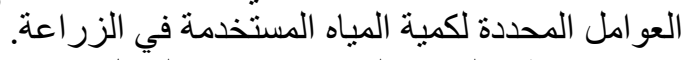

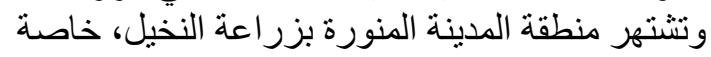

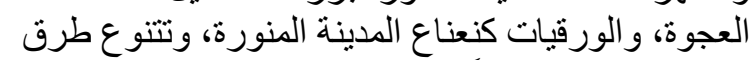

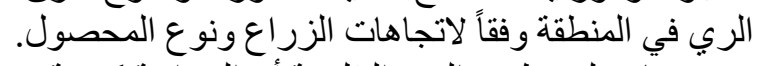

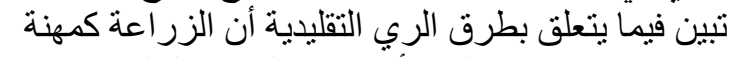

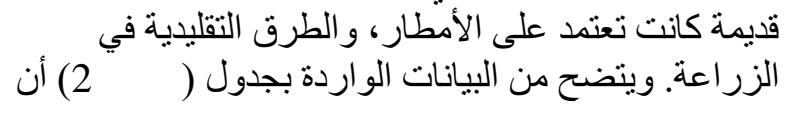

يجدف التغيير المعرفي إلى فهم الظواهر المحيطة

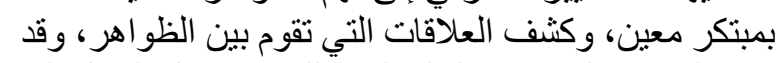

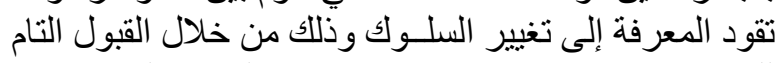

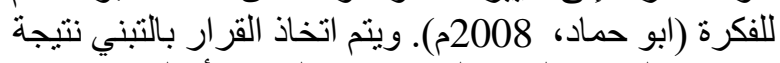

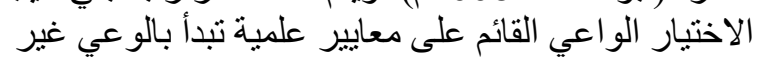

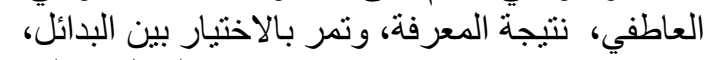

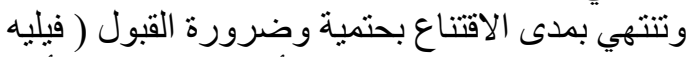

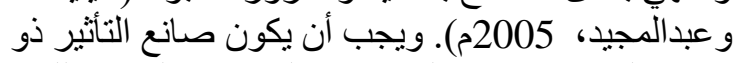

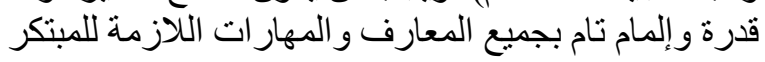
.(Goodwin and Schroeder, 1994))

\section{6. النتائج البحثية أولاً: الصفاتج البحثية الثخصية والاجتماعية والاقتصادية للمبحوثين}

تلعب الخصائص الثخين الثخية دور اً مهما في تحديد نوعية

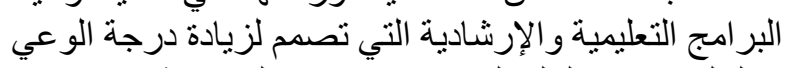

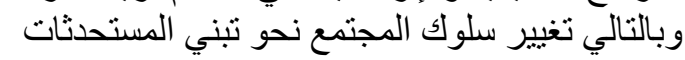

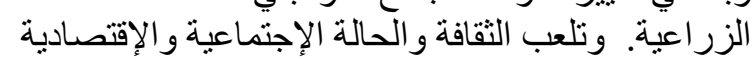

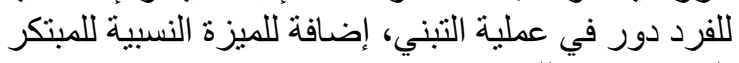

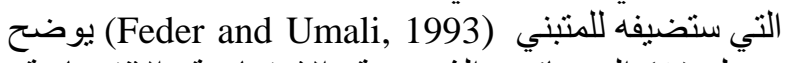
جدول ( 1) الخصائص الثخصية و الاجنماعية و الاقتصادية لإنية

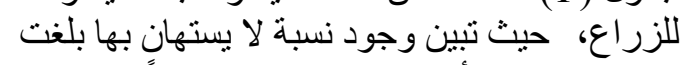

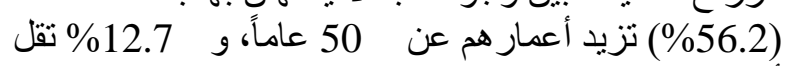
أعمار هم عن 40 سنة، و 29.1 29.

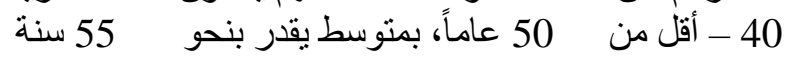

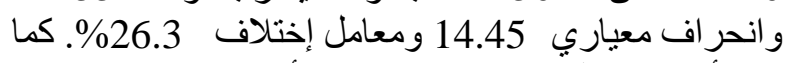

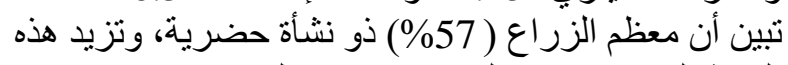

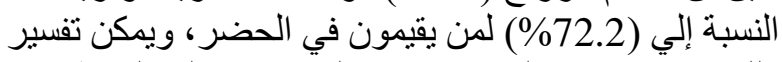

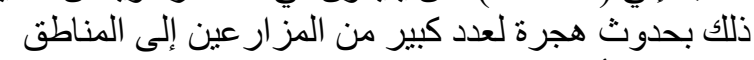

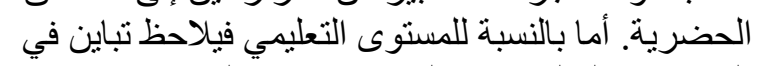

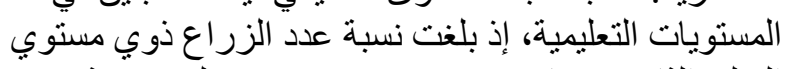

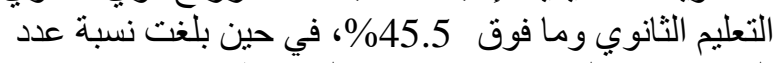

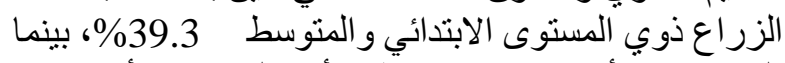

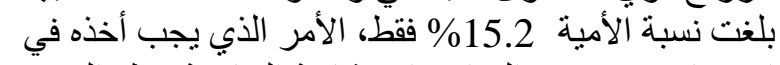

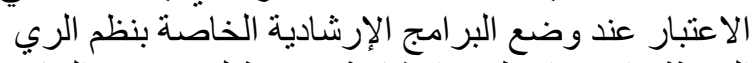

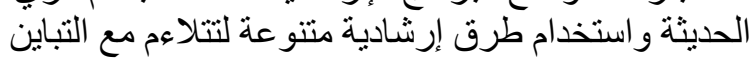

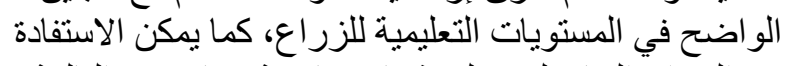

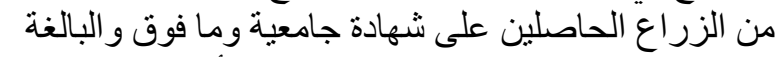

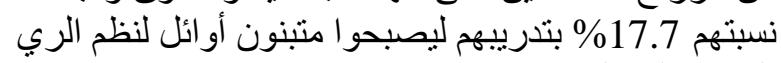
الحديثة المختلفة.

توضح بيانات نفس الجدول كبر حجم الأسرة نسبياً، إذ أن

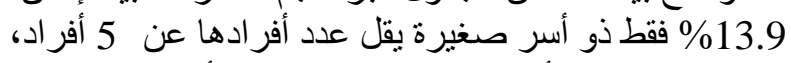

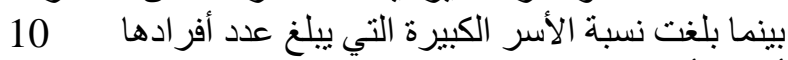

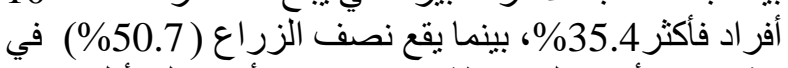

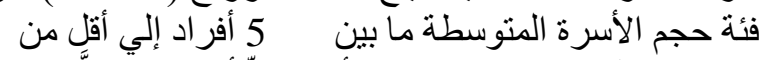

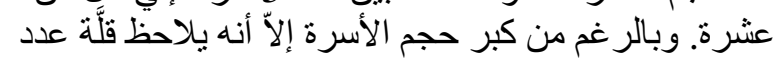

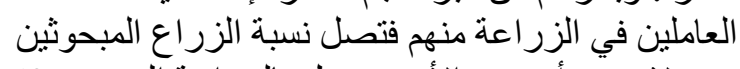

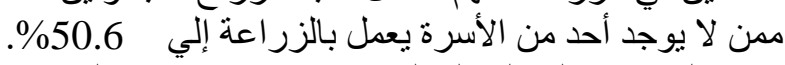

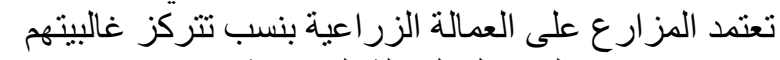

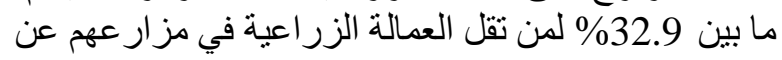


10.0\% عند درجة ثقة 95\%. و أخير أ تر اوحت نسبة عدد

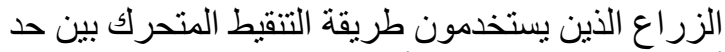
أدنى بلغ - 0.9\% وحد أعلى بلغ 5.9\% عند درجة ثقة \%95

ثُالثاً: المستوي المعرفي للزراع المبحوثين بنظم الري الحديثة

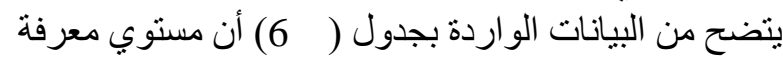

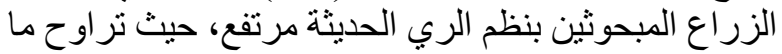

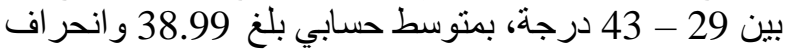

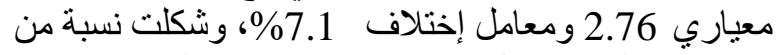

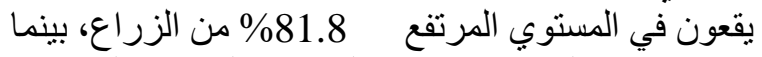

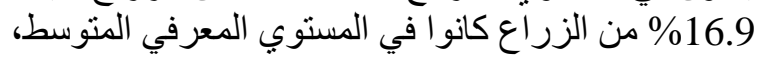

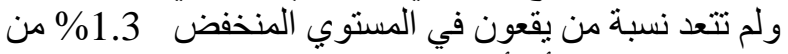

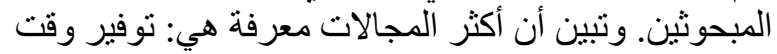

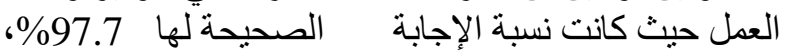

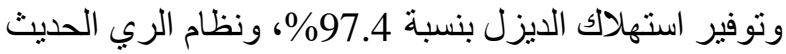

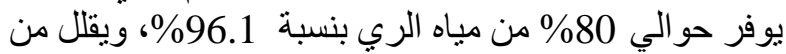

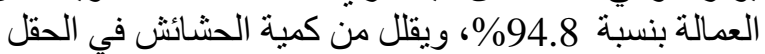

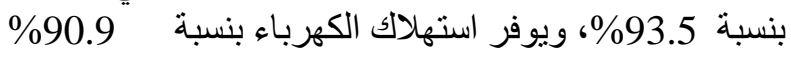
جدول (7). أما أقل المجالات معرفة فهي: يتم غمر الماء في

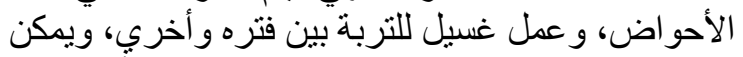

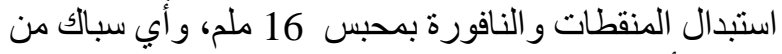

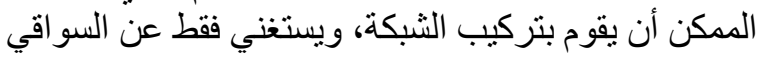

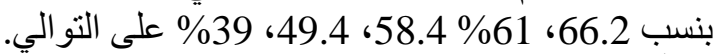

رابعاً: مشكلات نظم الري الحديثة في منطقة المدينة

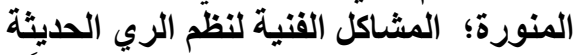

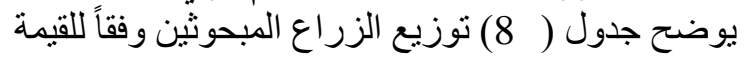

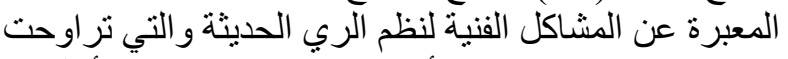
بين 16 درجة في حدها الأدني،

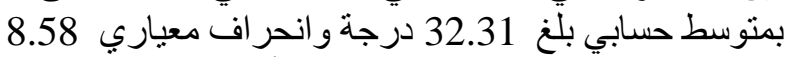
درجة ومعامل إختلاف 26.6\% \%

(85.4\%) من الزراع بقافعـون في فئتي المشاكل الفنية

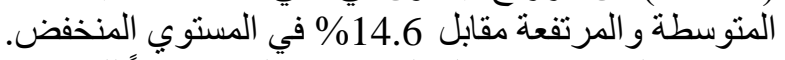

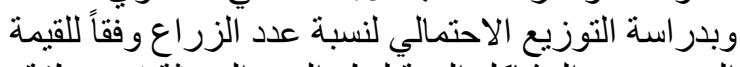

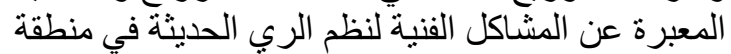

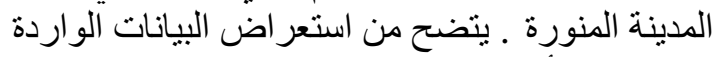

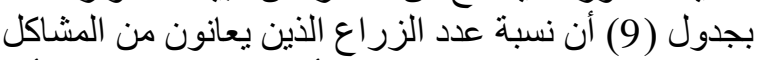

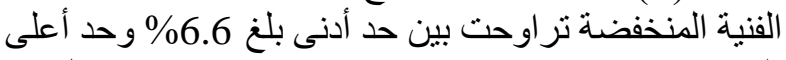

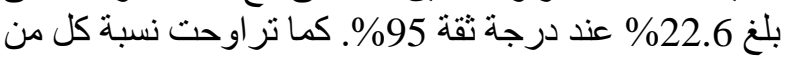
عدد الزراع الذين يعانون من المشاكل الفنية المتوسطة

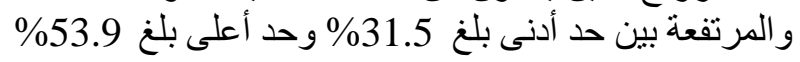

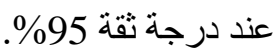

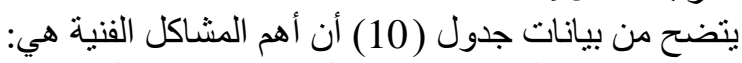

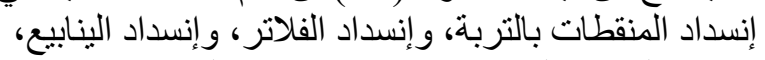

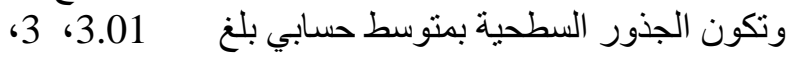

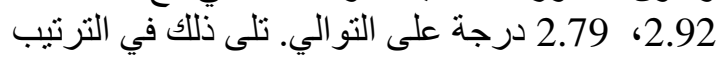

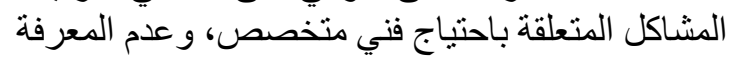

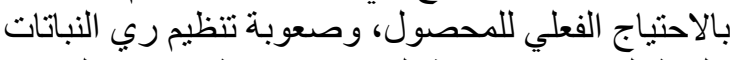

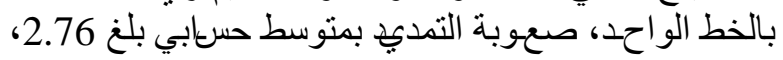

العادات و التقاليد الزر اعية لاتز ال تلعب دور في نوع وسائل

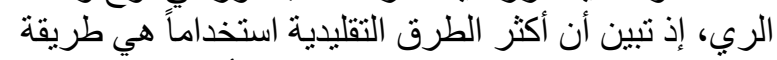

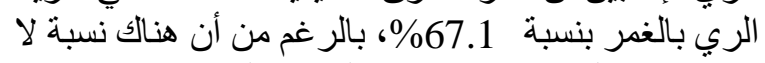

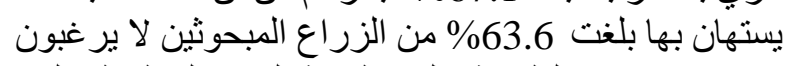

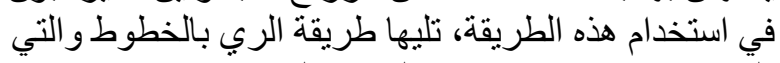

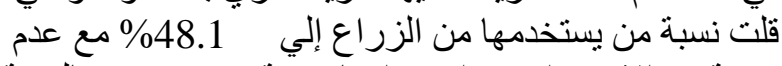

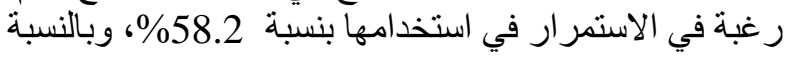

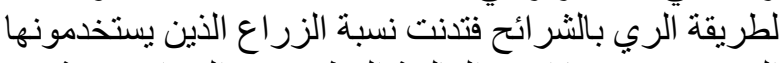

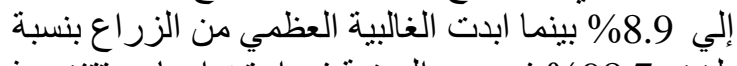

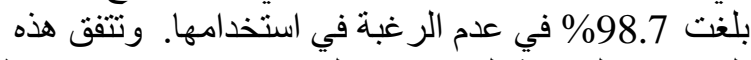

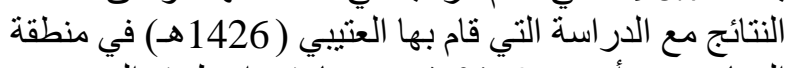

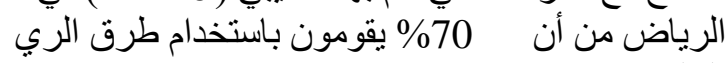

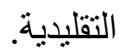

وبدر اسة التوزيع الاحتمالي لمدى استخدام الزراع المناع

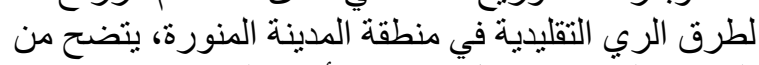

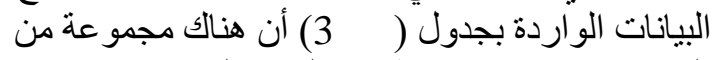

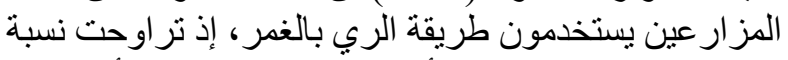

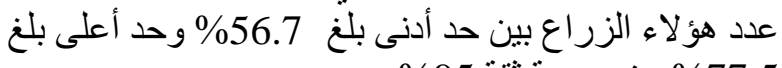

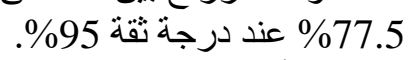
كما أن هناك عدد من الزرة واع بستخدمون طريقة الري

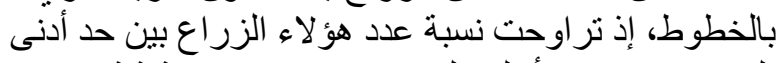

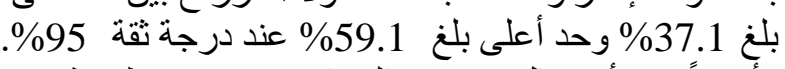

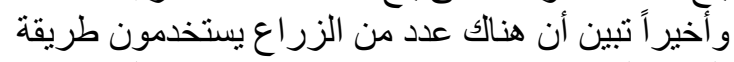

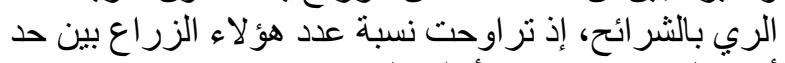

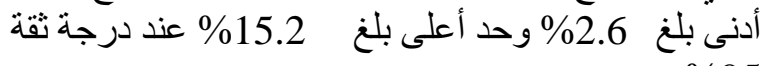
\%95

التوزيع الاحتمالي لنظم الري الحديثة

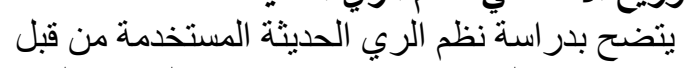

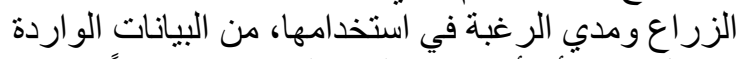

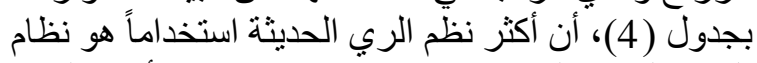

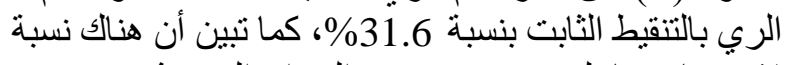

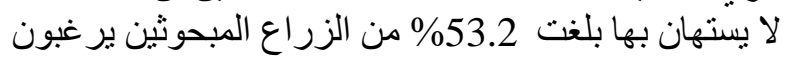

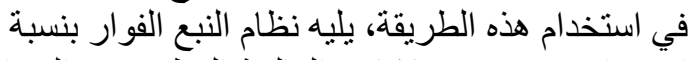

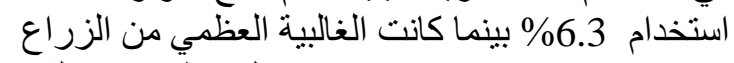

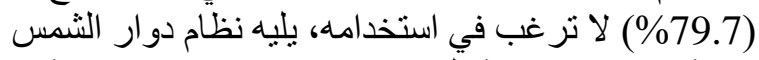
بنسبة استخدام ضعيفة بلغت

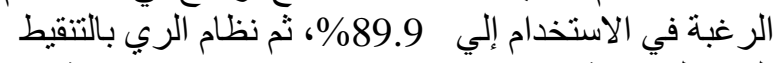

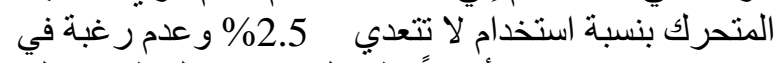

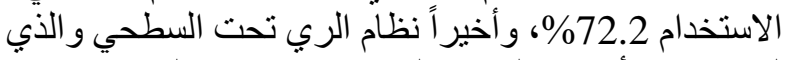

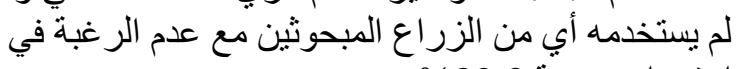

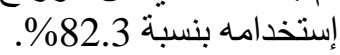

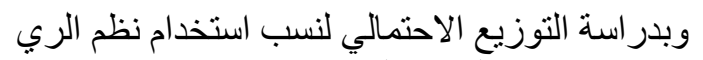

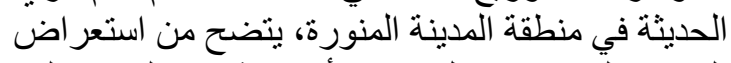

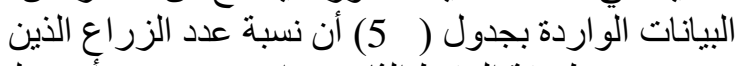

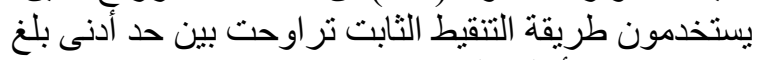

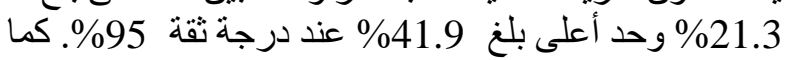

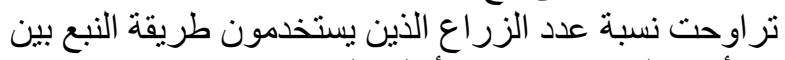

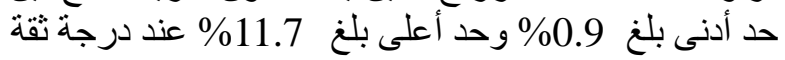

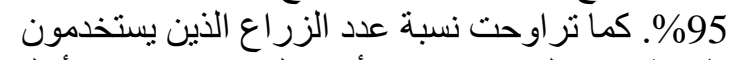
طريقة دو ار الثمس بين حد أدنى بلغ ب. 0.2\% وحد أعلى بلغ بلغ 
جدول (1): الصفات الاقتصادية والإجتماعية للزراع المبحوثين (ن = 158).

\begin{tabular}{|c|c|c|c|c|c|}
\hline$\%$ & عدد & الصفة & $\%$ & عدد & الصفة \\
\hline & & المستوي التعليمي: & & & العمر: \\
\hline 15.2 & 24 & 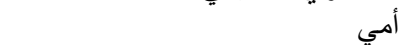 & 12.7 & 20 & أقل من 40 سنة \\
\hline 19 & 30 & إبتدائي & 29.1 & 46 & 40ـ أقل من 50 سنة \\
\hline 20.3 & 32 & متوسط & 21.5 & 34 & 50ـ أقل من 60 سنة \\
\hline 20.3 & 32 & ثانوي & 13.9 & 22 & 60ـ أقل من 70 سنة \\
\hline 7.6 & 12 & 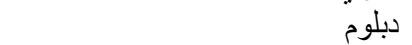 & 22.8 & 36 & ال 70 سنة فأكثر \\
\hline 15.2 & 24 & جامعي & & 55 & المتوسط الحسابي للعمر : الانحر اف \\
\hline 2.5 & 4 & مادستير العمالة الزر اعـة. & & 14.45 & المعياري : \\
\hline 32.9 & 52 & أفل من 3 عمال . & 57 & 90 & حضر " \\
\hline 45.6 & 72 & 3- أقل من 5 & 43 & 68 & ريف \\
\hline 17.7 & 28 & 5 - أقل من 10 & & & مكان الإقامة: \\
\hline \multirow[t]{2}{*}{3.8} & 6 & 10 عمال فأكثر & 72.2 & 114 & حضر \\
\hline & & المهنة الأساسية: & 27.8 & 44 & عديف أفراد الأسرة: \\
\hline 38 & 60 & موظف حكومي & 13.9 & 22 & أقل من 5 أفر اد \\
\hline 16.5 & 26 & متقاعد & 50.7 & 80 & 5 - أقل من 10 \\
\hline 15.2 & 24 & متسبب & 35.4 & 56 & 10 أفر اد فأكثر \\
\hline 13.9 & 20 & 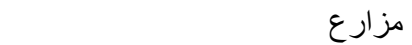 & & & عدد العاملين من الأسرة في الزراعة: \\
\hline 8.9 & 14 & عسكري & & & لا يو جد فرد يعمل بالزر اعةًّ \\
\hline 6.3 & 10 & تاجر & 50.6 & 80 & فرد واحد \\
\hline \multirow[t]{2}{*}{1.3} & 2 & موظف قطاع خاص & 35.4 & 56 & 2- أقل من 3 أفر اد \\
\hline & & المهنة الثانوية: & 7.6 & 12 & 4 أفر اد فأكثر \\
\hline 86.1 & 136 & مز ارع & 6.4 & 10 & \\
\hline 5 & 8 & متسبب & & & \\
\hline 1.3 & 2 & متقاعد & & & \\
\hline 7.6 & 12 & ليس لديه مهنة ثانوية & & & \\
\hline 12.7 & 20 & أقل من الزّراعَ السينوي: & 10.2 & 16 & ألقل من 3 آلافهري: ريال \\
\hline 20.3 & 32 & 25- أقل من 50 & 27.8 & 44 & 3- أقل من 5 \\
\hline 30.4 & 84 & 50- أقل من 100 & 20.3 & 32 & 5 \\
\hline 15.2 & 24 & 100- أقل من 150 & 8.8 & 14 & 8 \\
\hline 8.9 & 14 & 150 ألف ربال فأكثر & 19 & 30 & 10 آلاف ريال فأكثر \\
\hline 12.7 & 20 & غدي النخيل: & 13.9 & 22 & المسيرة مبين الكلية للمزرعة: \\
\hline 21.5 & 34 & أقل من 200 & & & اقل من 25 دونم \\
\hline 36.7 & 58 & 200- أقل من 500 & 17.7 & 28 & 25- أقل من 50 \\
\hline 24.1 & 38 & 500- أقل من 1000 & 35.5 & 56 & 50ـ أقل من 100 \\
\hline \multirow[t]{4}{*}{17.7} & 82 & 1000 نظلة فأكثر & 16.4 & 26 & 100- أقل من 200 \\
\hline & & & 19 & 30 & 200 دونم فأكثر \\
\hline & & عدد الآبار المستخذمة في الزراعة: & 11.4 & 18 & \\
\hline & & بئر واحد & & & النشاط الزراعي غير النخيل: \\
\hline 51.9 & 82 & بئران & & & \\
\hline 34.2 & 45 & 3 & 45.6 & 72 & محاصيل حقلية \\
\hline 8.9 & 14 & 4 أبار فأكثر & 19 & 30 & محاصيل خضر \\
\hline 5.1 & 8 & & 13.9 & 22 & محاصيل فاكهة \\
\hline
\end{tabular}

المصدر: جمعت وحسبت من البيانات الأولية لاستمارات الاستبيان التي تم تجميعها عام 2010م. 
جدول(2): طرق الري التقليدي المستخدمة من قبل المبحوثين ومدى رغبتهم في إستخدامها ( ن =158).

\begin{tabular}{|c|c|c|c|c|c|c|c|c|}
\hline \multicolumn{4}{|c|}{ مدى الرغبة في الاستخدام } & \multicolumn{4}{|c|}{ الاستخدام } & \multirow{3}{*}{ طرق التري } \\
\hline \multicolumn{2}{|c|}{ ل لا ير غب } & \multicolumn{2}{|c|}{ برغب } & \multicolumn{2}{|c|}{ لا يستخذم } & \multicolumn{2}{|c|}{ يستخدم } & \\
\hline$\%$ & عدد & $\%$ & عدد & $\%$ & عدد & $\%$ & عدد & \\
\hline 63.6 & 100 & 36.7 & 58 & 32.9 & 52 & 67.1 & 106 & بالغمر \\
\hline 58.2 & 92 & 41.8 & 66 & 51.9 & 82 & 48.1 & 76 & بالخطوط \\
\hline 98.7 & 156 & 1.3 & 2 & 91.1 & 144 & 8.9 & 14 & بالثر ائح \\
\hline
\end{tabular}

المصدر: جمعت وحسبت من البيانات الأولية لاستمارات الاستبيان التي تم تجميعها عام 2010م.

جدول (3): التوزيع الاحتمالي لاستخدام المزارعين لنظم الري التقليدية.

\begin{tabular}{|c|c|c|c|}
\hline 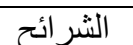 & 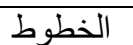 & 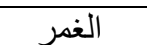 & 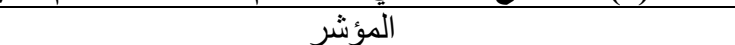 \\
\hline 0.089 & 0.481 & 0.671 & احتمال التوجه بالنسبة للفرد في العينة \\
\hline 0.911 & 0.519 & 0.329 & احتمال عدم التوجه بالنسبة للفرد \\
\hline 0.032 & 0.056 & 0.053 & الخطأ المعياري لاحتمال توجه الزر اع بالنسبة للفرد في العينة \\
\hline 0.063 & 0.110 & 0.104 & الخطأ المعياري عند درجة ثقة 95\% \\
\hline $\begin{array}{c} \pm 0.089 \\
0.063\end{array}$ & $\begin{array}{c} \pm 0.481 \\
0.110\end{array}$ & $\begin{array}{c} \pm 0.671 \\
0.104\end{array}$ & احتمال توجه الزر اع عند درجة ثقة 95\% \\
\hline $\begin{array}{c}\% 15.2 \\
\% 2.6 \\
\end{array}$ & $\begin{array}{l}\% 59.1 \\
\% 37.1 \\
\end{array}$ & $\begin{array}{l}\% 77.5 \\
\% 56.7\end{array}$ & الحبة توجه الأعلى الزراع عند درجة ثقة 95\%: \\
\hline
\end{tabular}

المصدر: جمعت وحسبت من البيانات الواردة بجدول (2).

جدول (4): طرق الري الحديثة المستخدمة من قبل المبحوثين ومدي رغبتهم في استخدامها (ن=-158).

\begin{tabular}{|c|c|c|c|c|c|c|c|c|}
\hline \multicolumn{4}{|c|}{ مدى الرغبة في الاستخدام } & \multicolumn{4}{|c|}{ الاستخدام } & \multirow[t]{3}{*}{ طرق الري الحديثة } \\
\hline \multicolumn{2}{|c|}{ لا ير غب } & \multicolumn{2}{|c|}{ برغب } & \multicolumn{2}{|c|}{ لا يستخذم } & \multicolumn{2}{|c|}{ يستخدم } & \\
\hline$\%$ & عدد & $\%$ & عدد & $\%$ & عدد & $\%$ & عدد & \\
\hline 46.8 & 74 & 53.2 & 84 & 68.4 & 108 & 31.6 & 50 & نظام ري تتقيط ثابت \\
\hline 79.7 & 126 & 20.4 & 32 & 93.7 & 148 & 6.3 & 10 & نظام النبع ( الفوار) \\
\hline 89.9 & 142 & 10.1 & 16 & 94.9 & 150 & 5.1 & 8 & نظام دوار الثمس \\
\hline 72.2 & 114 & 27.8 & 44 & 97.5 & 154 & 2.5 & 4 & نظام ري تنقيط متحرك \\
\hline 82.3 & 130 & 17.7 & 28 & 100 & 158 & - & - & نظام ري تحت سطحي \\
\hline
\end{tabular}

المصدر: جمعت وحسبت من البيانات الأولية لاستمارات الاستبيان التي تم تجميعها عام 2010م.

جدول (5) : التوزيع الاحتمالي لاستخدام المزارعين لنظم الري الحديثة.

\begin{tabular}{|c|c|c|c|c|}
\hline تنقيط متحرك & 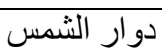 & ينبع & تنقيط ثابت & المؤشر \\
\hline 0.025 & 0.051 & 0.063 & 0.316 & احتمال الاستخدام بالنسبة للفرد في العينة \\
\hline 0.975 & 0.949 & 0.937 & 0.684 & احتمال عدم الاستخدام بالنسبة للفرد \\
\hline 0.018 & 0.025 & 0.027 & 0.052 & 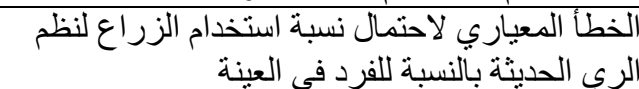 \\
\hline 0.034 & 0.049 & 0.054 & 0.103 & الخطأ المعياري عند درجة ثقة 95\% \\
\hline $\begin{array}{c} \pm 0.025 \\
0.034 \\
\end{array}$ & $\begin{array}{c} \pm 0.051 \\
0.049 \\
\end{array}$ & $\begin{array}{c} \pm 0.063 \\
0.054\end{array}$ & $\begin{array}{c} \pm 0.316 \\
0.103\end{array}$ & احتمال نسبة الأستخدام عند درجة ثقة 95\% \\
\hline $\begin{array}{l}\% 5.9 \\
\% 0.9-\end{array}$ & $\begin{array}{c}\% 10.0 \\
\% 0.2\end{array}$ & $\begin{array}{c}\% 11.7 \\
\% 0.9\end{array}$ & $\begin{array}{l}\% 41.9 \\
\% 21.3\end{array}$ & الحد الأعلى استخدام نظم الري الحديثة عند درجة ثقة 95\%: \\
\hline
\end{tabular}

المصدر: جمعت وحسبت من البيانات الواردة بجدول (4). 
جدول (6): توزيع الزراع المبحوثين وفقاً للقيمة الرقمية المعبرة عن مستواهم المعرفي بنظم الري الحديثة.

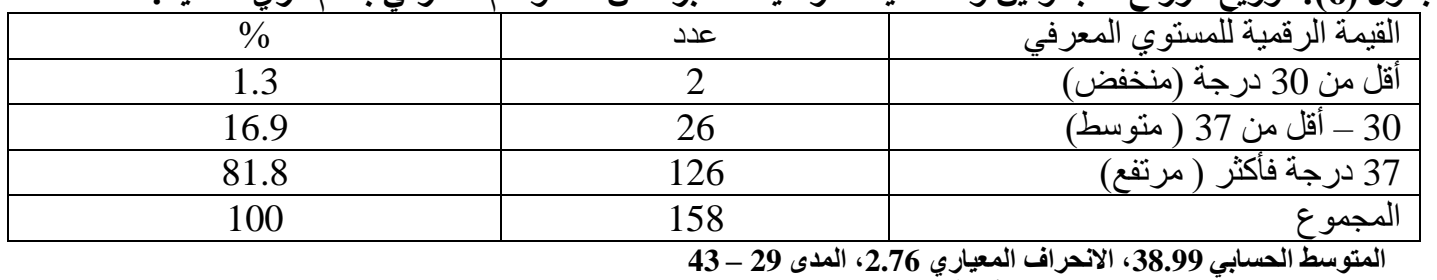

المصدر: جمعت وحسبت من البيانات الأولية لأستمارات الاستبيان التي تم تجميعها عام 2010م.

جدول (7): المستوي المعرفي للزراع المبحوثين بنظم الري الحديثة (ن -158).

\begin{tabular}{|c|c|c|c|c|}
\hline \multicolumn{2}{|c|}{ إجابة خاطئة } & \multicolumn{2}{|c|}{ إجابة صحيحة } & \multirow[t]{2}{*}{ 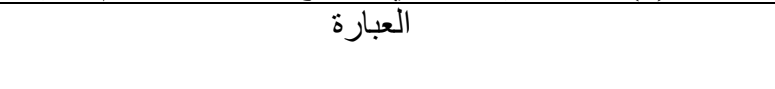 } \\
\hline$\%$ & عدد & $\%$ & عدد & \\
\hline 1.3 & 2 & 97.7 & 76 & يوفر وقت العمل \\
\hline 2.6 & 2 & 97.4 & 75 & يوفر إستهلاك الديزل \\
\hline 3.9 & 3 & 96.1 & 74 & نظام الري الحديث يوفر حو الي 80\% من مياه الري \\
\hline 5.2 & 4 & 94.8 & 73 & يقلل من العمالة \\
\hline 6.5 & 5 & 93.5 & 72 & يقلل من كمية الحشائش في الحقل \\
\hline 9.1 & 7 & 90.9 & 70 & يوفر إستهلاك الكهرباء \\
\hline 10.4 & 8 & 89.6 & 69 & يحتاج دفع قوي للماء \\
\hline 10.4 & 8 & 89.6 & 69 & بتم تمديد شبكة ليات متكاملة \\
\hline 11.7 & 9 & 88.3 & 68 & يتصل بكل شجرة لوحدها \\
\hline 16.9 & 13 & 83.1 & 64 & يحتاج إلى فلاتر \\
\hline 19.5 & 15 & 80.5 & 62 & يزيد عدد المزروعات \\
\hline 24.7 & 19 & 75.3 & 58 & يحتاج إلي مر اقبة المنقطات \\
\hline 26 & 20 & 74 & 57 & الأسمدة العضوية تقلل تركيز الأملاح \\
\hline 29.9 & 23 & 70.1 & 54 & بناء الشبكة يحتاج منخفض \\
\hline 32.5 & 25 & 67.5 & 52 & تحتاج الثبكة منظم ضغط \\
\hline 32.5 & 25 & 67.5 & 52 & إضافة مادة التبن في الأخو اض تقلل المياه بنسبة تصل إلي 10\% \\
\hline 32.5 & 25 & 67.5 & 52 & يحتاج فني متخصص \\
\hline 33.8 & 26 & 66.2 & 51 & ينتم غمر الّماء في الأحواض \\
\hline 39 & 30 & 61 & 47 & يجب عمل غسيل للتربة بين فترهو أخري \\
\hline 41.6 & 32 & 58.4 & 45 & ممكن إستبدال المنقطات و النافورة بمحبس 16 ملم \\
\hline 50.6 & 39 & 49.4 & 38 & أي سباك من الممكن أن يقوم بتركيب الثبكة \\
\hline 61 & 47 & 39 & 30 & يستغني فقط عن السو اقي \\
\hline
\end{tabular}

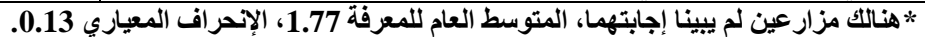

المصدر: جمعت وحسبت من البيانات الأولية لاستمارات الاستبيان المعان التي تم تجميعها عام 2010م.

جدول (8): توزيع الزراع المبحوثين وفقاً للقيمة المعبرة عن المشاكل الفنية لنظم الري الحديثة.

\begin{tabular}{|c|c|c|}
\hline$\%$ & عدد & القيمة الرقمية للمشاكل الفنية \\
\hline 14.6 & 22 & أقل من 24 درجة (منخفض) \\
\hline 42.7 & 64 & 24 - أقل من 36 ( منوسط) \\
\hline 42.7 & 64 & 36 درجة فأكثر ( مرتفع) \\
\hline 100 & 158 & المجموع \\
\hline
\end{tabular}

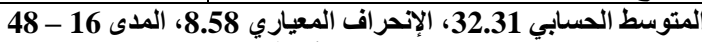

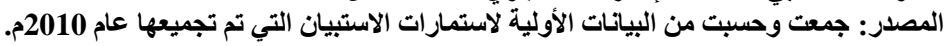


معياري 0.81، 0.90، 0.79، 0.88، 0.86، 0.44، درجة

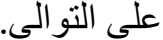

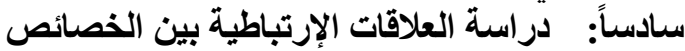

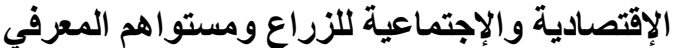

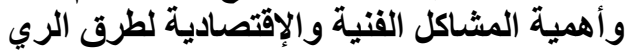

الحديثة

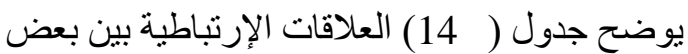

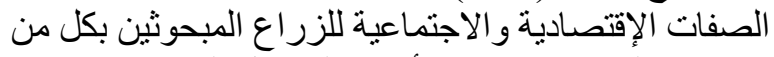

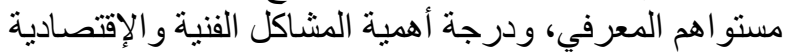
لطرق الري الحديثة في منطقة المدينة المنورة

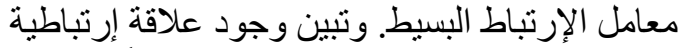

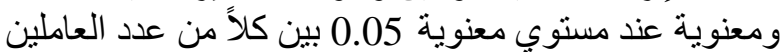

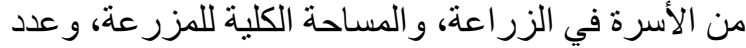

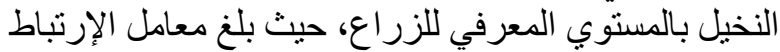

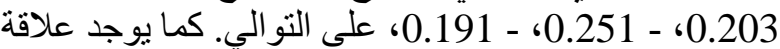

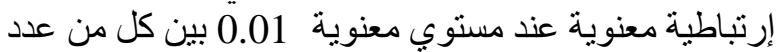

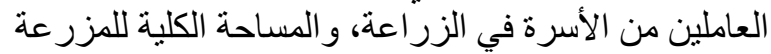

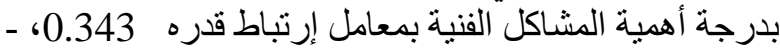

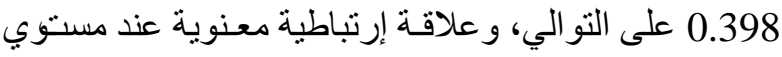
معنوية - مين

0.05

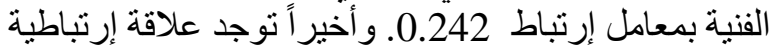

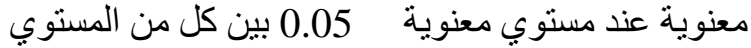

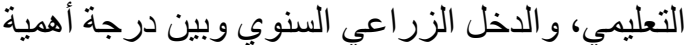
المشاكل الإقتصادية بمعامل إرتباط قدره -

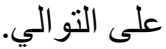

7. المناقشة والتوصيات

تتسم منطقة المدينة المنورة بزر اعة المنات النخيل، و الورقيات

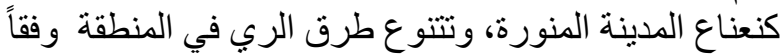

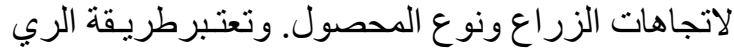

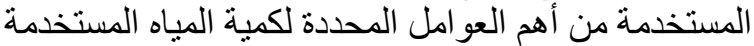

في الزر اعة. وبالر غم من شح المياه في منطقة المدينة

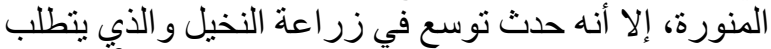

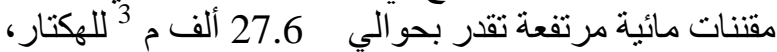

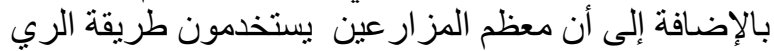

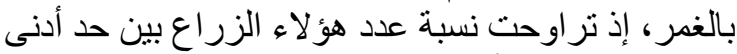

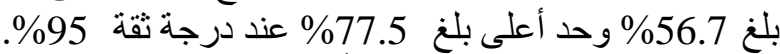

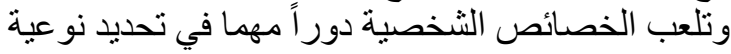

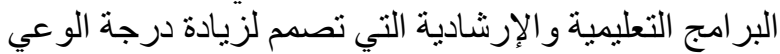

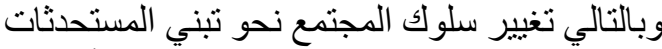

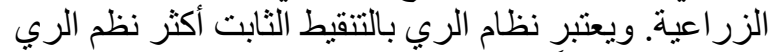

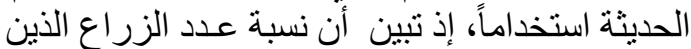

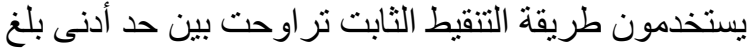

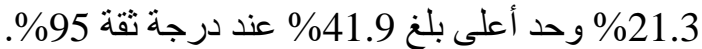

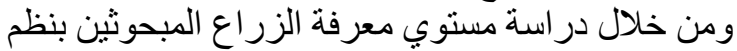

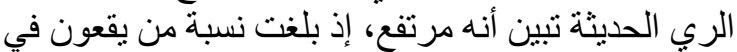

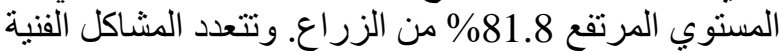

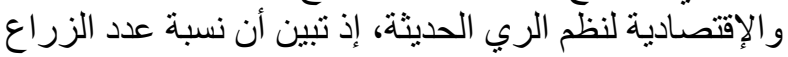

2.72، 2.68، 2.6 درجة على التو الي. أما فيما يتعلق بما ير اه المبحوثون أَقل المشكلات الفنية

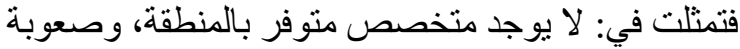

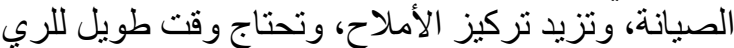

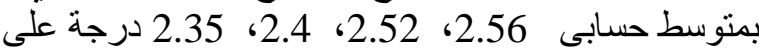

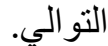

المشاكل الاقتصادية لنظم الري الحديثة

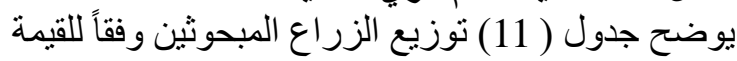
المعبرة عن المشاكل الإقتصادية لنظم الري الري الحديثة و التئي

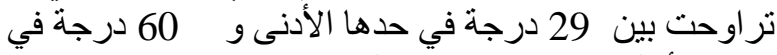

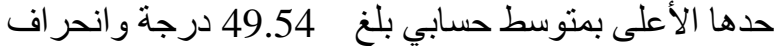

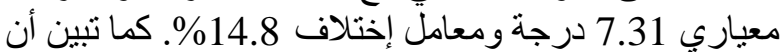

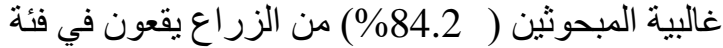

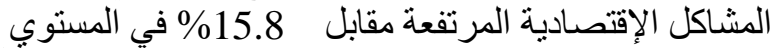

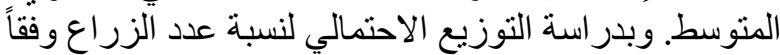

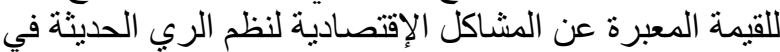

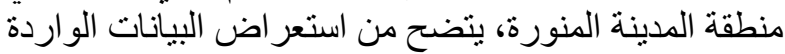

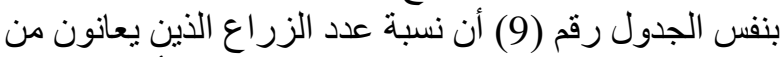

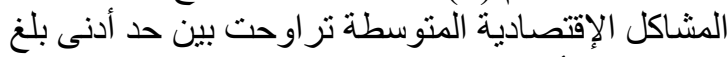

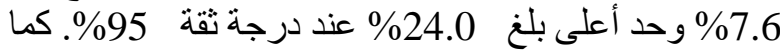
تر اوحت نسبة كل من عدد الزر العاع الذين يعانون من المشاكل الإقتصادية المرتفعة بين حد أدنى بلغ 76.0\%

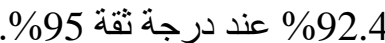

ويتضح من البيانات الواردة بجدول (

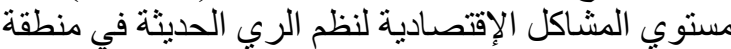

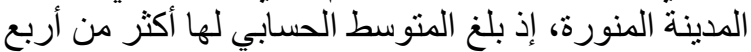

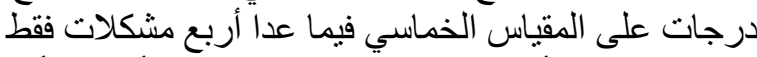

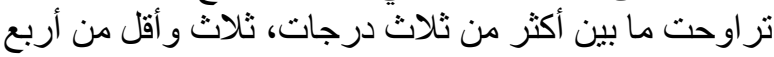

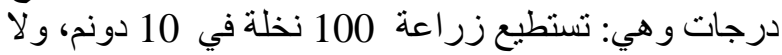
تحتاج إلي تسوية سطح التربة، وتكاليف بناء الثبكة ل 10

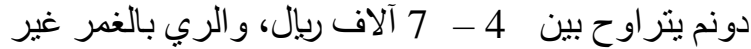

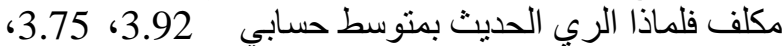
3.64، 3.36 درجة على التو الي.

خامساً: مصادر معلومات الزراع التراع لاستخذامات المياه في الأغراض الزراعية

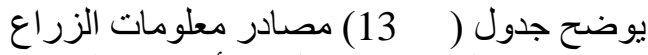

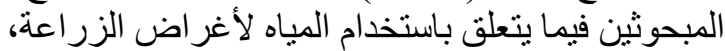

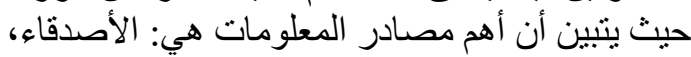

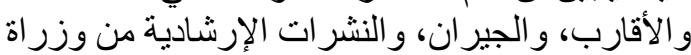
الزر اعة، و الكتيبات الإرشادية، و المطويات الإنية الإرشادية

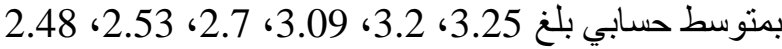

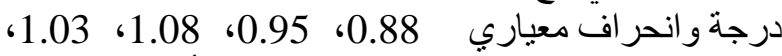
0.98، 0.99 درجة على التو الي. بينما كانت أقل المصادي التهادر

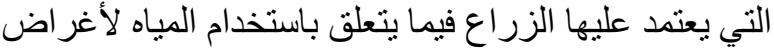

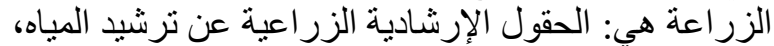

و المحاضر أت عن المياه و الترشيد، و الأفلام الزئة الزر اعية،

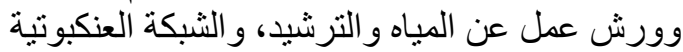

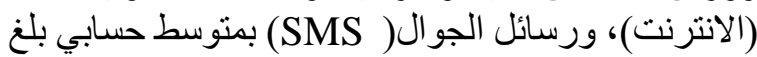

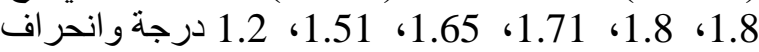


جدول (9): التوزيع الاحتمالي للقيمة المعبرة عن المشاكل الفتية والإقتصادية لنظم الري الحديثة.

\begin{tabular}{|c|c|c|c|c|}
\hline \multicolumn{2}{|c|}{ المشاكل الإقتصادية } & \multicolumn{2}{|c|}{ المشاكل الفنية } & \multirow[t]{2}{*}{ المؤشر } \\
\hline المرتفعة & المتوسطة & المتوسطة & المنخفضة & \\
\hline 0.842 & 0.158 & 0.427 & 0.146 & احتمال أهمية المشكلة بالنسبة للفرد في العينة \\
\hline 0.158 & 0.842 & 0.573 & 0.854 & احتمال عدم الأهمية بالنسبة للفرد \\
\hline 0.042 & 0.042 & 0.057 & 0.041 & في العينة المعياري لاحتمال أهمية المشكلة بالنسبة للفرد \\
\hline 0.082 & 0.082 & 0.112 & 0.080 & الخطأ المعياري عند درجة ثقة 95\% \\
\hline $\begin{array}{l} \pm 0.842 \\
0.082\end{array}$ & $\begin{array}{l} \pm 0.158 \\
0.082\end{array}$ & $\begin{array}{c} \pm 0.427 \\
0.112\end{array}$ & $\begin{array}{c} \pm 0.146 \\
0.08\end{array}$ & احتمال توجه الزراع عند درجة ثقة 95\% \\
\hline $\begin{array}{l}\% 92.4 \\
\% 76.0\end{array}$ & $\begin{array}{l}\% 24.0 \\
\% 7.6\end{array}$ & $\begin{array}{l}\% 53.9 \\
\% 31.5\end{array}$ & $\begin{array}{l}\% 22.6 \\
\% 6.6\end{array}$ & الحدبة أهمية المشكلة عند درجة ثقة 95\%: \\
\hline
\end{tabular}

المصدر: جمعت وحسبت من البيانات الواردة بجدولي (11،8).

جدول (10): المشاكل الفنية لنظم الري الحديثة من منظور الزراع المبحوثين (ن =158).

\begin{tabular}{|c|c|c|c|c|c|c|}
\hline & & & & & & مدى وجود المشكلة \\
\hline الانحر اف & المتوسط & لا توجد & صغير & متوسط & كبير & \\
\hline المعياري & الحسابي & $\%$ & $\%$ & $\%$ & $\%$ & المشكلة \\
\hline 0.99 & 3.01 & 6.7 & 28 & 22.7 & 42.7 & انسداد المنقطات بالتربة \\
\hline 1 & 3.00 & 8 & 25.3 & 25.3 & 41.3 & انسداد الفلاتز \\
\hline 1.04 & 2.92 & 9.3 & 29.3 & 21.3 & 40 & انسداد الينابيع \\
\hline 1.03 & 2.79 & 12 & 29.3 & 26.7 & 32 & تكون الجذور سطحية \\
\hline 1.04 & 2.76 & 12 & 32 & 24 & 32 & تحتاج فني متخصص \\
\hline 1.09 & 2.72 & 14.7 & 32 & 20 & 33 & عدم المعرفة بالاحتياج الفعلي للمحصول \\
\hline 1 & 2.68 & 12 & 34.7 & 26.7 & 26.7 & صعوبة تتظيم ري النباتات بالخط الو احد \\
\hline 0.96 & 2.6 & 10.7 & 41.3 & 25.3 & 22.7 & صعوبة التمديد \\
\hline 1.08 & 2.56 & 18.7 & 33.3 & 21.3 & 26.7 & لا بوجد متخصص متوفر بالمنطقة \\
\hline 0.95 & 2.52 & 13.3 & 40 & 28 & 18.7 & صعوبة الصبانة \\
\hline 0.92 & 2.4 & 14.7 & 45.3 & 25.3 & 14.7 & تزيد تركيز الأملاح \\
\hline 1.02 & 2.35 & 21.3 & 41.3 & 18.7 & 18.7 & تحتاج وقت طويل للري \\
\hline
\end{tabular}
المصدر: جمعت وحسبت من البيانات الأولية لاستمارات الاستبيان التي تم تجميعها عام 2010م.

\begin{tabular}{|c|c|c|}
\hline$\%$ & عدد & القيمة الرقمية للمشاكل الإقتصادية \\
\hline- & - & أقل من 28 درجة (منخفض) \\
\hline 15.8 & 25 & 28 - أقل من 44 ( منوسط) \\
\hline 84.2 & 133 & 44 درجة فأكثر ( مرتفع) \\
\hline 100 & 158 & المجموع \\
\hline
\end{tabular}

المصدر: جمعت وحسبت من البيانات الأولية لاستمارات الاستبيان التي تم تجميعها عام 2010م. 
جدول (12): المشاكل الإقتصادية لنظم الري الحديثة من منظور الزراع المبحوثين (ن =158).

\begin{tabular}{|c|c|c|c|c|c|c|c|c|c|c|c|c|}
\hline \multirow{3}{*}{ الإنحعياري } & \multirow{3}{*}{ الحستوسطي } & \multirow{2}{*}{\multicolumn{2}{|c|}{ غير موافث }} & \multirow{2}{*}{\multicolumn{2}{|c|}{ غير موافق }} & \multirow{2}{*}{\multicolumn{2}{|c|}{ محايد }} & \multirow{2}{*}{\multicolumn{2}{|c|}{ موافق }} & \multirow{2}{*}{\multicolumn{2}{|c|}{ موافق بشدة }} & \multirow{3}{*}{ مدى الموافقة } \\
\hline & & & & & & & & & & & & \\
\hline & & $\%$ & عدد & $\%$ & عدد & $\%$ & عدد & $\%$ & عدد & $\%$ & عدد & \\
\hline 0.74 & 4.64 & 1.3 & 2 & - & - & 7.9 & 12 & 14.5 & 22 & 76.3 & 116 & البنوك التجارية لاط النشاط \\
\hline 0.75 & 4.61 & - & - & 2.6 & 4 & 7.9 & 12 & 15.8 & 24 & 73.7 & 112 & شتركامل مع التقبط هذا النوع لأ \\
\hline 0.96 & 4.51 & 2.6 & 4 & 2.6 & 4 & 9.2 & 14 & 11.8 & 18 & 73.7 & 112 & 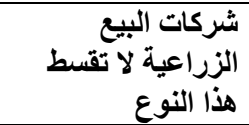 \\
\hline 0.85 & 4.42 & - & - & 5.3 & 8 & 7.9 & 12 & 26.3 & 40 & 60.5 & 92 & تكاليف الشبكة عالية \\
\hline 0.95 & 4.29 & - & - & 6.6 & 10 & 14.5 & 22 & 22.4 & 34 & 56.6 & 68 & عدم وجود ممول \\
\hline 1.01 & 4.28 & 1.3 & 2 & 6.6 & 10 & 13.2 & 20 & 21.1 & 32 & 57.9 & 88 & تكاليف العمالة الفنية \\
\hline 1.26 & 4.11 & 6.6 & 10 & 6.6 & 10 & 14.5 & 22 & 14.5 & 22 & 57.9 & 88 & شروطه معقدة \\
\hline 1.1 & 4.01 & 1.3 & 2 & 10.5 & 16 & 19.7 & 30 & 22.4 & 34 & 46.1 & 70 & الثراليف ما بعد \\
\hline 1.1 & 3.92 & 3.9 & 6 & 7.9 & 12 & 17.1 & 26 & 34.2 & 54 & 36.8 & 56 & تخلة في 10 دونة 100 \\
\hline 1.34 & 3.75 & 10.5 & 16 & 10.5 & 16 & 9.2 & 14 & 32.9 & 50 & 36.8 & 56 & لا تحتاج إلي تسوية \\
\hline 1.09 & 3.64 & 3.9 & 6 & 6.6 & 10 & 39.5 & 60 & 21.1 & 32 & 28.9 & 44 & 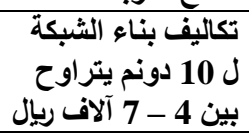 \\
\hline 1.38 & 3.36 & 10.5 & 16 & 21.1 & 32 & 21.1 & 32 & 17.1 & 26 & 30.3 & 46 & الريف فلالغمر غير الريز \\
\hline
\end{tabular}
المصدر: جمعت وحسبت من البيانات الأوليّة لاستمارات الاستبيان التي تم تجميعها عام 2010م.

ومن ناحية أخرى فقد تبين وجود علاقات ارتباطية بين

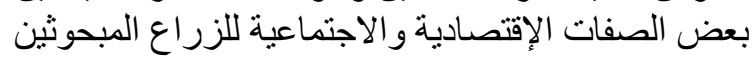

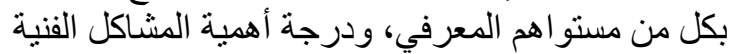
و الإقتصادية لطرق الري الحديثة في منطقة المدينة المنورة.

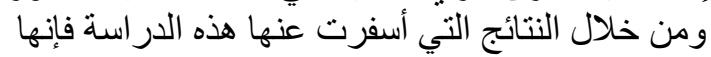
توصي بالآتي: (1) ضرورة تبني صندوق التنمية الزر اعية
الذين يعانون من المشاكل الفنية المتوسطة و المرتفعة بين

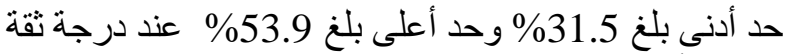

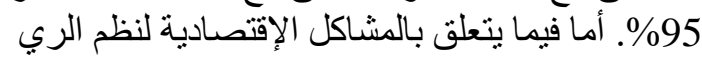

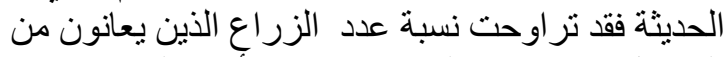

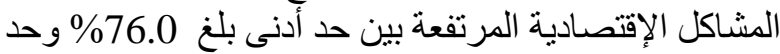

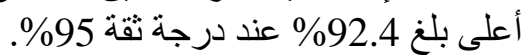




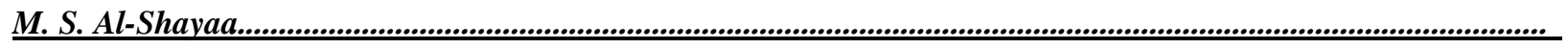

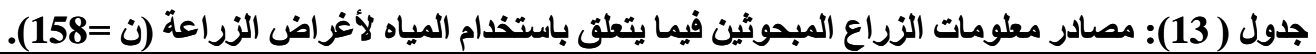

\begin{tabular}{|c|c|c|c|c|c|c|c|c|c|c|}
\hline \multirow{2}{*}{ ال الإنحرياري } & \multirow{2}{*}{ الحسابي } & \multicolumn{2}{|c|}{ لا أستخدمها } & \multicolumn{2}{|c|}{ نادراً } & \multicolumn{2}{|c|}{ أحياناً } & \multicolumn{2}{|c|}{ دائماً } & \multirow{2}{*}{ مصدر المعلومات درجة الإعتماد } \\
\hline & & $\%$ & عدد & $\%$ & عدد & $\%$ & عدد & $\%$ & عدد & \\
\hline 0.88 & 3.25 & 7.6 & 12 & 6.3 & 10 & 39.2 & 62 & 46.8 & 74 & الأصدقاء \\
\hline 0.95 & 3.2 & 10.1 & 16 & 6.3 & 10 & 36.7 & 58 & 46.8 & 74 & الأقّارب \\
\hline 1.08 & 3.09 & 13.9 & 22 & 11.4 & 18 & 26.6 & 42 & 48.1 & 76 & الجيران \\
\hline 1.03 & 2.7 & 13.9 & 22 & 30.4 & 44 & 27.8 & 44 & 27.8 & 44 & نشرات إرشادية من وزراة \\
\hline 0.98 & 2.53 & 15.2 & 24 & 36.7 & 58 & 27.8 & 44 & 20.3 & 32 & كتيبات إرشادية \\
\hline 0.99 & 2.48 & 15.2 & 24 & 41.8 & 66 & 22.8 & 36 & 20.3 & 32 & مطويات إرشادية \\
\hline 0.97 & 2.46 & 19 & 30 & 31.6 & 50 & 34.2 & 54 & 15.2 & 24 & مجلات زر اعية \\
\hline 0.90 & 2.39 & 16.5 & 26 & 39.2 & 62 & 32.9 & 52 & 11.4 & 18 & ملصقات إرشادية \\
\hline 0.85 & 2.3 & 20.3 & 32 & 34.2 & 54 & 40.5 & 64 & 5.1 & 8 & المرشد الزراعي \\
\hline 1.02 & 2.27 & 24.1 & 38 & 43 & 68 & 15.2 & 24 & 17.7 & 28 & نشرات إرشادية من وزارة المياه \\
\hline 0.75 & 2.14 & 21.5 & 34 & 43 & 68 & 35.4 & 56 & - & - & برامج إذاعية زراعية عن الترشيد \\
\hline 0.84 & 2.10 & 26.6 & 42 & 40.5 & 64 & 29.1 & 46 & 3.8 & 6 & الترشيد تلفزيونية زراعية عن \\
\hline 0.96 & 2.08 & 32.9 & 52 & 35.4 & 56 & 22.8 & 36 & 8.9 & 14 & معارض زر اعية \\
\hline 0.81 & 1.8 & 41.8 & 66 & 39.2 & 62 & 16.5 & 26 & 2.5 & 4 & المياه إرشادية زر اعية عن ترشيد \\
\hline 0.90 & 1.8 & 48.1 & 76 & 27.8 & 44 & 20.3 & 32 & 3.8 & 6 & محاضر ات عن المياه و الترشيد \\
\hline 0.79 & 1.71 & 46.8 & 74 & 38 & 60 & 12.7 & 20 & 2.5 & 4 & الأفلام الزراعية \\
\hline 0.88 & 1.65 & 57 & 90 & 26.6 & 42 & 11.4 & 18 & 5.1 & 8 & ورش عمل عن المياه و الترشيد \\
\hline 0.86 & 1.51 & 67.1 & 106 & 21.5 & 34 & 5.1 & 8 & 6.3 & 10 & الثبكة العنكبوتية (الانترنت) \\
\hline 0.44 & 1.2 & 81 & 128 & 17.7 & 28 & 1.3 & 2 & - & - & رسائل الجوال(SMS) \\
\hline
\end{tabular}

جدول (14): العلاقة الإرتباطية بين بعض الصفات الإقتصادية والاجتماعية للزراع المبحوثين بكل من مستواهم

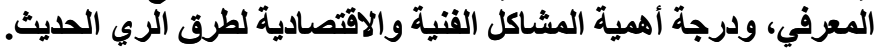

\begin{tabular}{|c|c|c|c|}
\hline درجة أهمية المشاكل الإقتصادية & درجة أهمية المشاكل الفنية & المستوي المعرفي & العوامل المستقلة \\
\hline $0.153-$ & $* * 0.343$ & $* 0.203$ & الزرد العة العلين من الأسرة في \\
\hline$* 0.253-$ & $0.175-$ & $0.069-$ & المستوي التعليمي \\
\hline$* 0.216$ & $* 0.242$ & $0.003-$ & الدخل الزراعي السنوي \\
\hline 0.012 & $* * 0.398-$ & $* 0.251-$ & المساحة الكلية للمزر عة \\
\hline **0.76 - & $0.070-$ & *0.191 - & عدد النخيل \\
\hline
\end{tabular}

المصدر: جمعت وحسبت من البيانات الأولية لاستمارات الآستبيان التي تم تجميعها مغوية عام 2010 م

من خلال توفير التمويل اللازم للتحول من الري التمام التقليدي

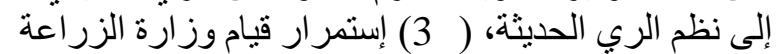

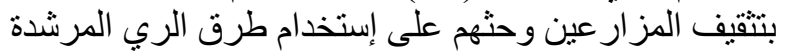

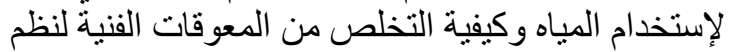

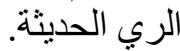

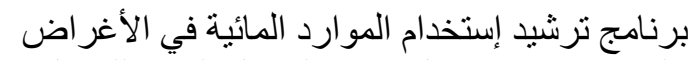

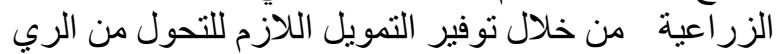

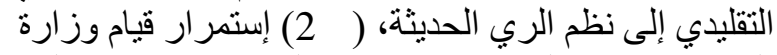

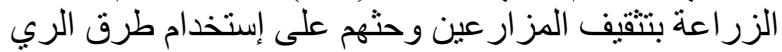

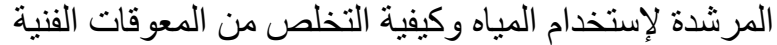

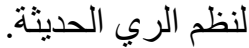




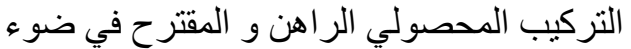

$$
\begin{aligned}
& \text { اعتبار ات الأمن المائي بالمملكة العربية السعودية في المبنة }
\end{aligned}
$$

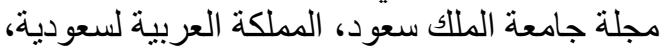

$$
\begin{aligned}
& \text { م17، العلوم الزراعية (1): 19-44. }
\end{aligned}
$$

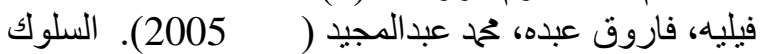

$$
\begin{aligned}
& \text { التنظيمي في ادارة المؤسسات التعليمية، دار المسيرة }
\end{aligned}
$$

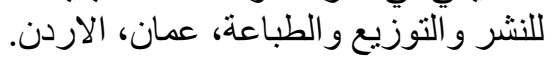

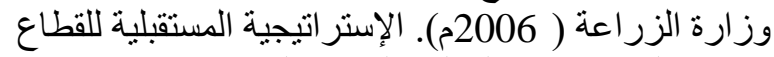

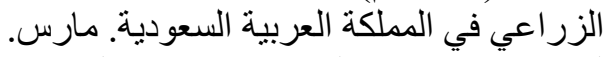

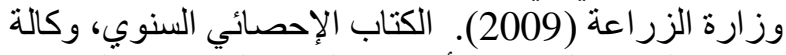

$$
\begin{aligned}
& \text { الوز ارة لنثؤون الأبحاث و التنمية الزر اعية، الرياض. }
\end{aligned}
$$

Faruqui N. I., Biswas A. K. and Bino M. J. (2001). Water in Islam, New York, United Nation University.

Feder G., and Umali D. (1993). The adoption of agricultural innovations: a review.

Technological Forecasting and Social Change 43, 215-239.

Goodwin BK. and Schroeder TC. (1994). Human capital, producer education programs, and adoption of forward-pricing methods. American Journal of Agricultural Economics 76, 936-947.

Hungerford H. R., and Volk T. L. (1990). Changing learner behavior through environment education. Paper presented at the Marcg (1990) World Conference on education for Al-meeting Basic Learning Needs. Journal of Environmental Education, pp8-12.

Makridakis S., Wheelwights S., and McGee., V.E. (1993). Forecasting Methods and Application. $2^{\text {nd }}$ ed New York: Johns Wiley and Sons.

Park M. (2003). Children's bedroom are media havens. Media use statistics children, youth and adults. [on-line] www.med.sc.ed.108/mediause.htm.

Rogers Everett M. (1995). Diffusion of Innovations. $4^{\text {th }}$ ed. New York: Free Press.

William D. L. (1990). Focusing agricultural education research: strategies for the discipline. Journal of Agricultural Education, 32 (1): 22-29.

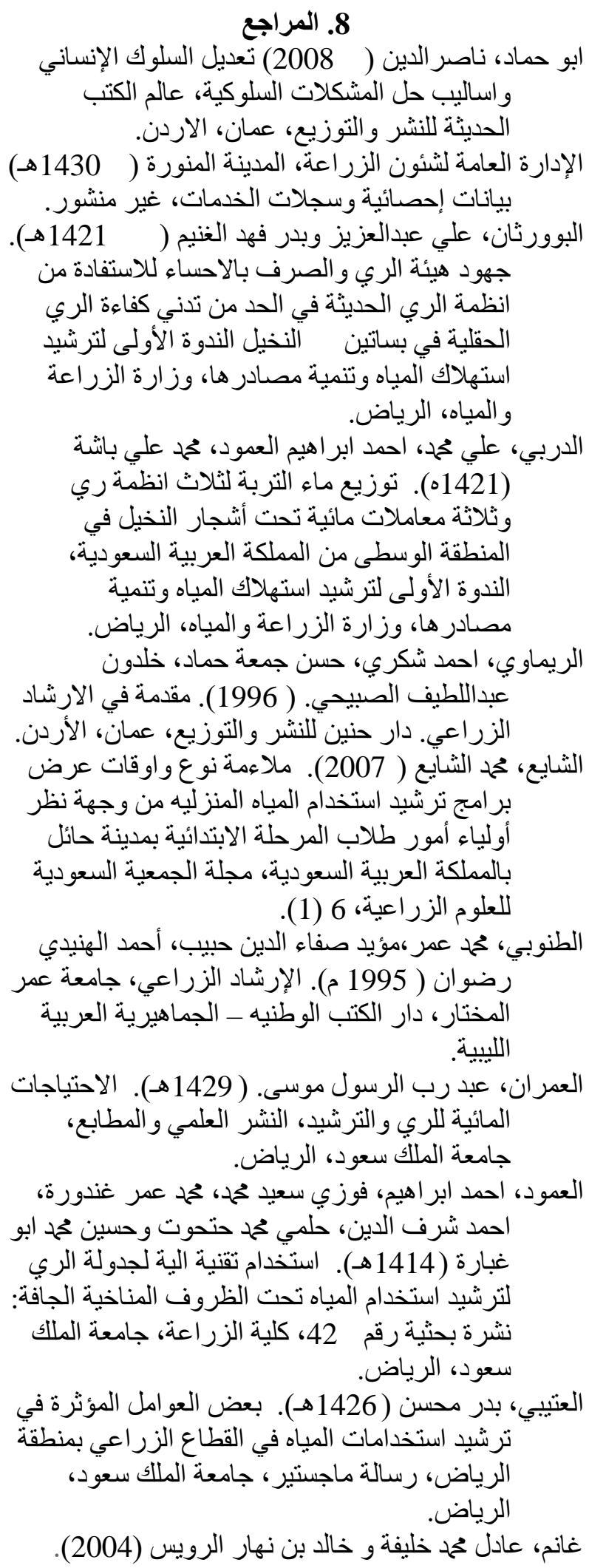

